\title{
أثر استخدام القصة في تدريس التربية الفنية لتنمية بعض مهارات الخيال الفني لدى طلاب المرحلة المتوسطة
}

\author{
إعداد \\ د. أحمد إبراهيم أحمد آلـ ساعد الغامدي الكي

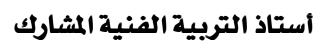 \\ كلية التربية جامعة الباحة
}

مجلة بعوث التربية النوعية ـ جامعة المنصورة

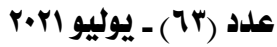




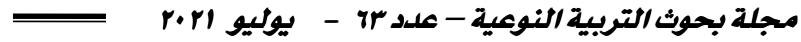

أثر استخدام القصة في تدريس التربية الفنية لتنمية بعض ههارات الخيال الفني

لدى طلاب المرحلة المتوسطة

\author{
إعداد \\ دـ أحمد إبراهيم أحمد آل ساعد الغامديُ*ـ
}

u̇il|

هدف البحث إلى تنمية مهارات الخيال الفني لدى طلاب المرحلة المتوسطة باستخدام

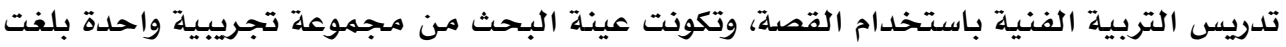

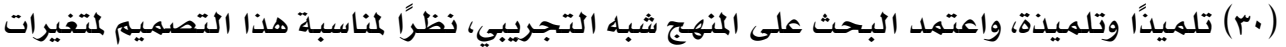

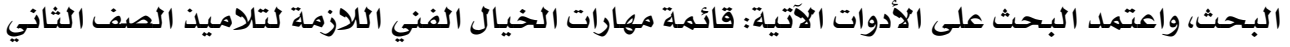

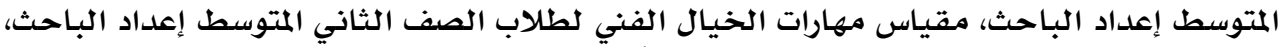

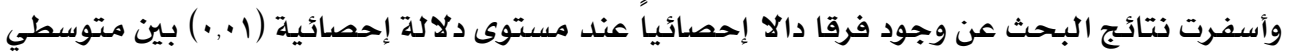

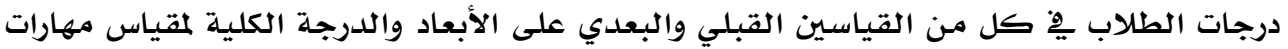

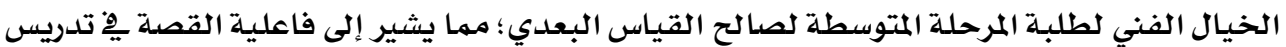

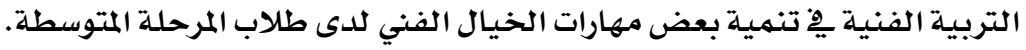

الكلمات المفتاحية: القصة؛ التربية الفنية؛ مهارات الخيال الفني؛ طلاب المرحلة المتوسطة

همدهة البحث:

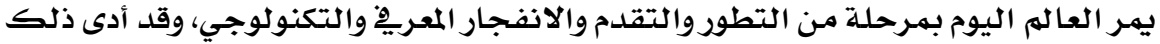

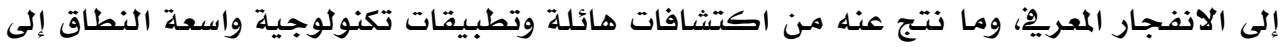

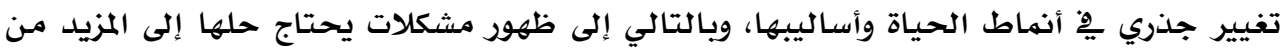
التطور والتقدم (Valkanova \& Watts, 2007).

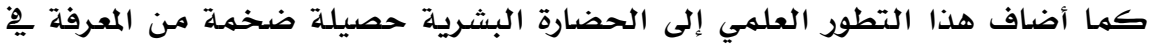

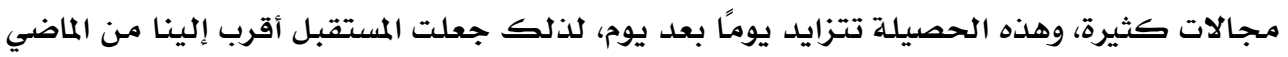

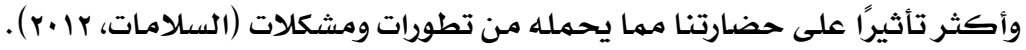

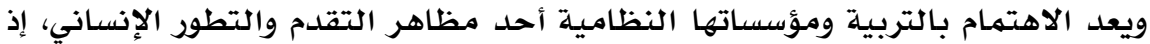

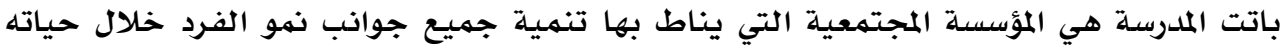

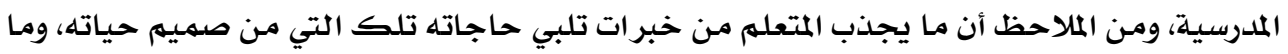

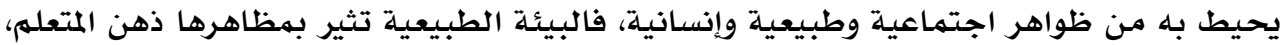




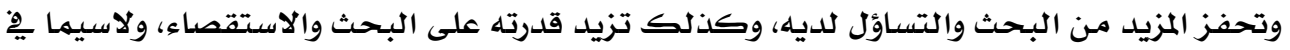

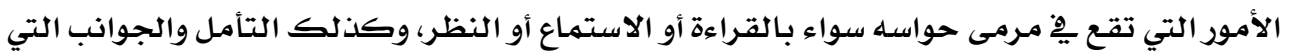
تحث على الخيال (ديمة الحريات، عا ـr) ).

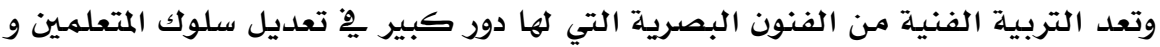

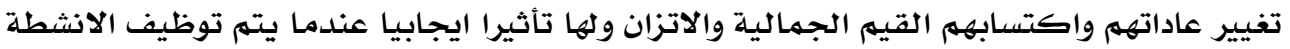

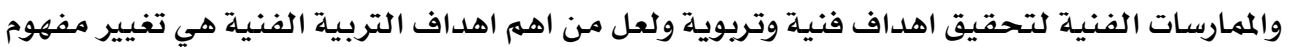

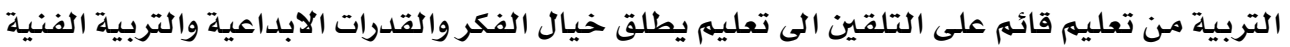

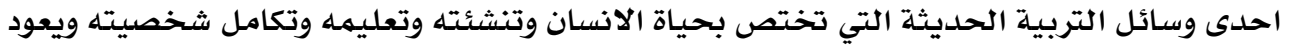

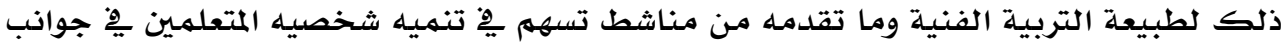

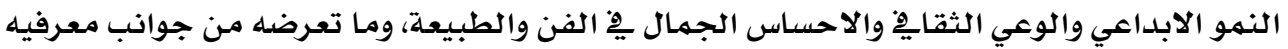

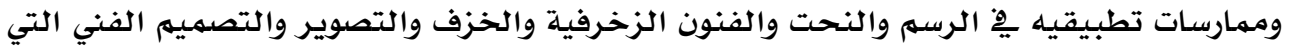
تؤدي الى تنميه الطاقات الابداعية والمهارات الفنية للطلبة (Arnheim, 2013). ولا ريب أن مناهج التربية الفنية تقدم محتوى يتمركز حول العديد من الجوانب التي

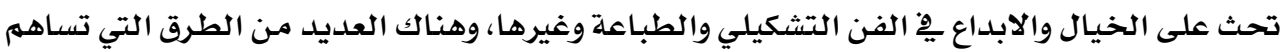

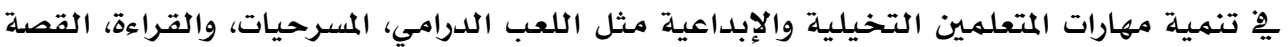
Myers \& Antonelli, 2012).

فالقصة تساعد المتعلم على تكوين مفاهيم جديدة وخبرات نافعة، وتساعده ِِّ بناء الشخصية، وذلك عن طريق الأنشطة التلقائية كرواية المعلم القصة على التلاميذ، أو استماع المتعلهم للقصة من خلال الوسائط المتعددة. ويشير الهريِّ (1999، به) إلى أن القصة لون من ألوان اللعب الإيهامي الذي يحتاج إليه

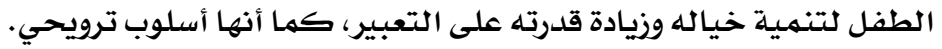

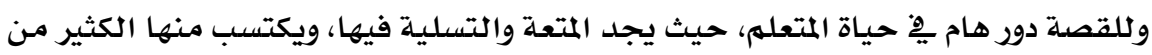

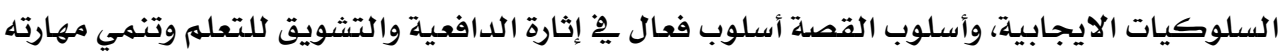
فِ التفكير التخيلي وتنميـة الخيال لديه. فالخيال هو العملية الكلية التي تضم كل العمليات الفرعية الخاصدة بالتخيل، وهو ذلك

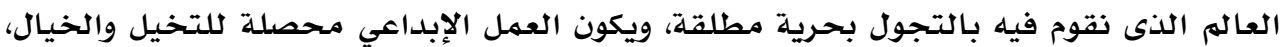

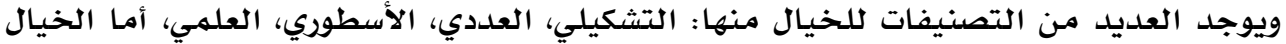

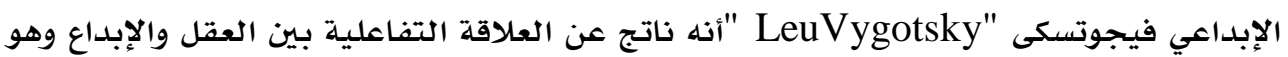

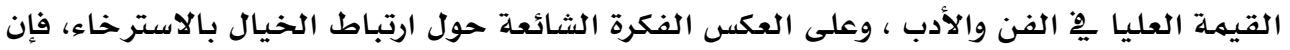

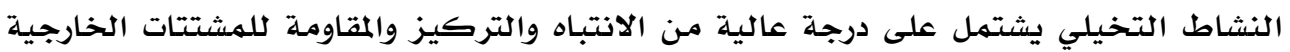

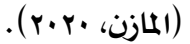




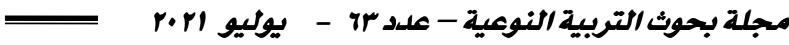

ويمارس الخيال دوره ِِّ العلهم ِِّ اختراع الأجهزة والأدوات، وفى اقتراح النماذج، وصياغة

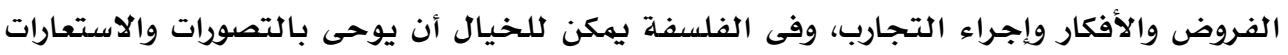

.(Muller \& Brook, 2014)

وبناءً على ذلك؛ فإن الغرض من هذه الدراسـة هو تقصي أثر استخدام القصة يِّ تدريس

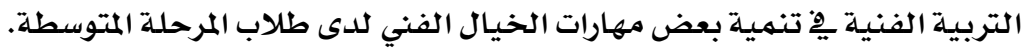

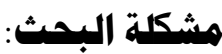

نبعت مشكلة البحث من خلال الشواهد التالية:

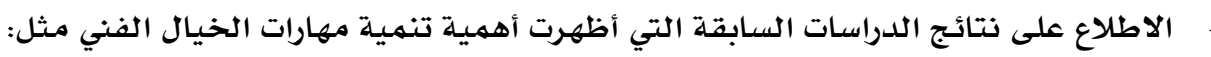

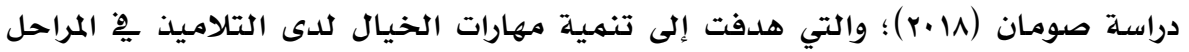

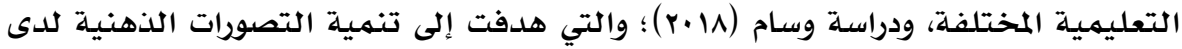

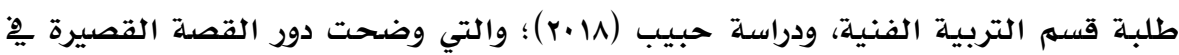

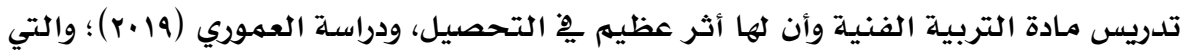

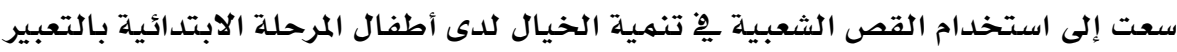

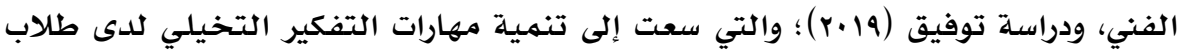

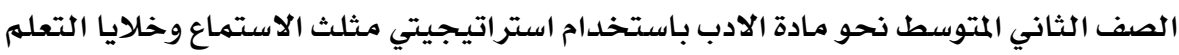

$$
\text { وغيرها من الدراسات. }
$$

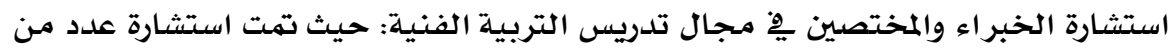

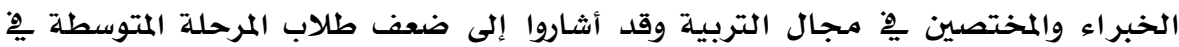

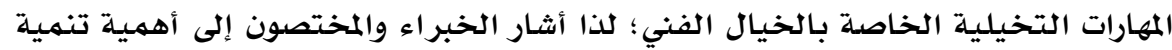

$$
\text { تلك المهارات لدى المتعلمهين. }
$$

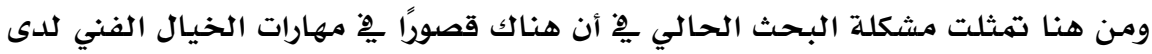

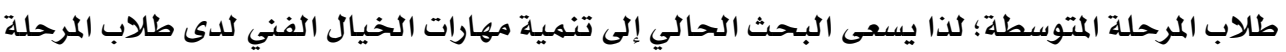
المتوسطة باستخدام القصة.

$$
\text { • ما مهارات الخيال الفني المناسبة لطلاب المرحلة المتوسطة؟ }
$$

• ما نوع القصص المناسبة لطلاب الصف الثاني بالمرحلة المتوسطة؟ • ما فاعلية استخدام القصة يِّنمية بعض مهارات الخيال الفني لطلاب الصف الثاني بالمرحلة المتوسطة؟ مأفلة أهداف البحث:

$$
\text { هدف البحث الحالي إلى: التئي }
$$

التعرف على مهارات الخيال الفني المناسبة لطلاب الصف الثاني بالمرحلة المتوسطة. 
• التعرف على فاعلية استخدام القصة يْ تنمية مهارات الخيال لطلاب الصف الثاني بالمرحلة

\section{المتوسطة.

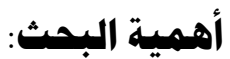

\section{الأهمية النظرية:}

وتبرز الأهميـة النظريـة لهذا البحث يْ تقديم إطار نظري متعلق بأسلوب القصة ومهارات الخيال الفني المناسبة لطلاب الصف الثاني بالمرحلة المتوسطة.

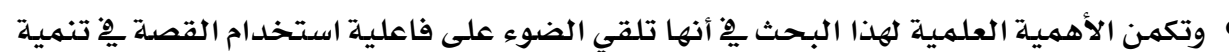
مهارات الخيال الفني لدى لطلاب الصف الثاني بالمرحلة المتوسطة.

\section{الأهمية التطبيقية:}

• تفيد المعلمـين يف التعرف على مهارات الخيال الفني المناسبـة لتلاميذ الصف الثاني المتوسط، وكذلك استخدام أسلوب القصدة يِّة تدريس مـادة التربية الفنية.

ه تفيد المتخصصين فِ التربية الفنية كالمشرفين التربويين على تدريب المعلمهين أثناء فترة

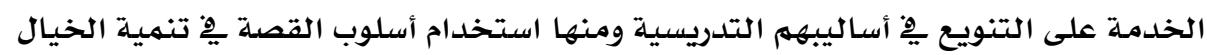

$$
\text { الفني لدى تلاميذ الصف الثاني المتوسط. }
$$

• تفيد واضعي مناهـج مـادة التربية الفنيـة بتضمهين أسلوب القصدة فِ تدريس التربية الفنية؛ مها

$$
\text { هدورد البحثيد فاعلية المادة. }
$$

ץ- الحدود الموضوعيةة: بعض دروس التربية الفنية المعدة بأسلوب القصة ومتضهنة مهارات

$$
\text { الخيال الفني المراد تنهيتها لتلاميذ الصف الثاني المتوسط. }
$$

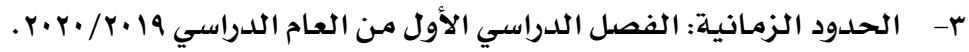

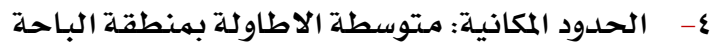

هم:

|القمهة:

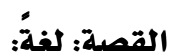

الخبر وهو القصص. وقص عليّ خبرهُ يقصسه قصاً وقصصاً والقصص: بالخبر المقصوص،

بالفتح: وضع موضـع المصدر حتى غَلب عليه والقصص، بكسر القاف: جمـع القصلة التي تكتب (ابن

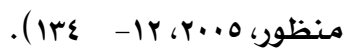


مجموعة من الأحداث التي يرويها الكاتب، وهي تتناول حادثة واحدة أو عدة حوادث تتعلق

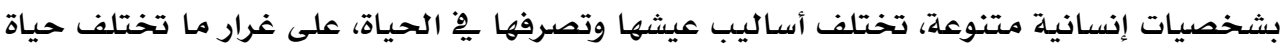

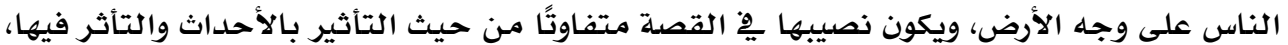
وتصور فترة كاملة من حياة خاصة (سليمان وآخرون، ا... ب). وعرفتها دحلان (11 +r) بأنها شكل روائي يتميز بالإثارة والجاذبية تقدم بواسطته المعلومات

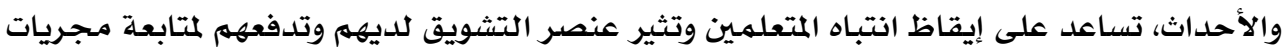
الدروس. ويعرفها الباحث إجرائيًا بأنها لون أدبي قديم ومعاصر يسرد موقف أو مجموعة مواقف

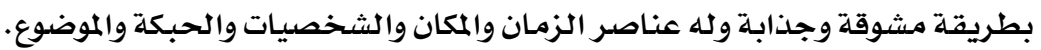
الخيال:

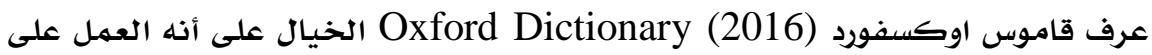
تكوين صور جديدة غير موجودة بالواقع الخارجي، ولا يتم استكشافها عبر الحواس.

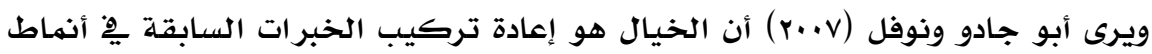

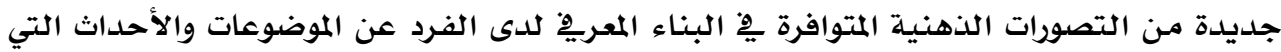

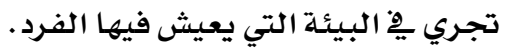

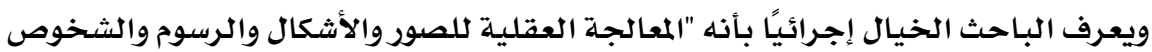

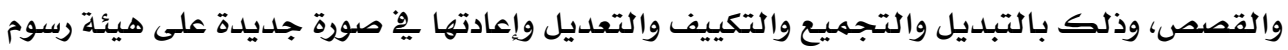

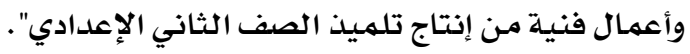

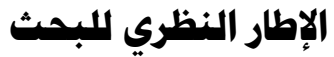 المهور الأول التزبية الفنية:}

مفهوم التربية الفنية.

تُعرف على أنها نشاط يقوم بقوم به الفرد ليعبر عن عالمه الخاص، ويشكل تشكيلا فنيا

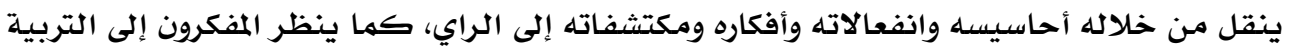

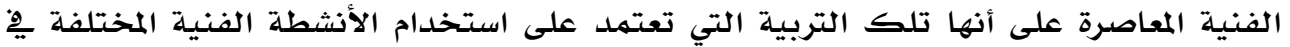

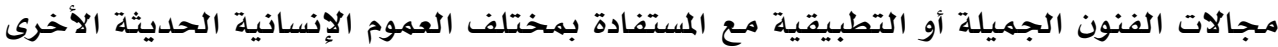

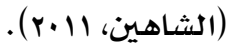

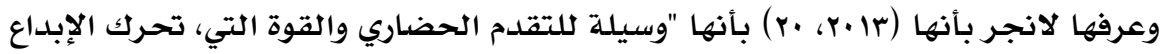

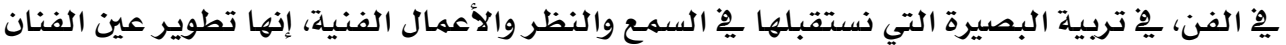

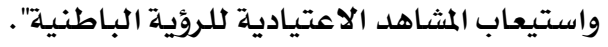




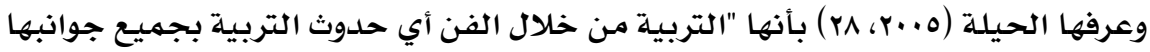

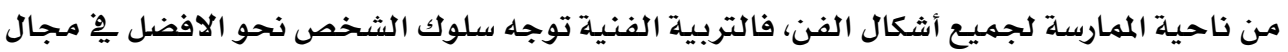

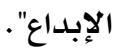

أهداف التربية الفنية

تسعى التربية الفنية إلى اكتشاف الموهوبين ورعايتهم بوسائل متنوعة، من أهمها

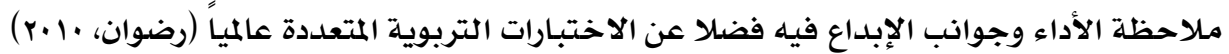
وذكر (عبدالقادر، 10 r) الأهداف العام للتربية الفنية التي تسعي إلى تحقيقها على

النحو الاتي: - n و

ا. حلدث التلاميذ على الاهتمام بالطبيعة وتقديرها، وتنمية النواحي الوجدانية والعاطفية

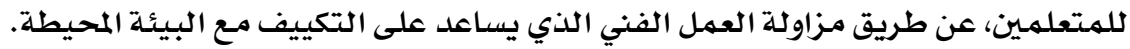

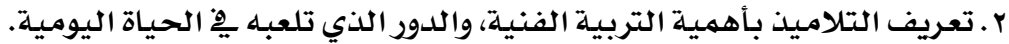

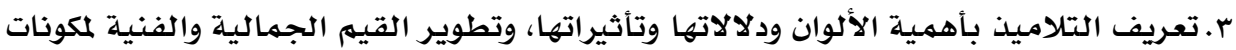

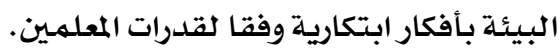

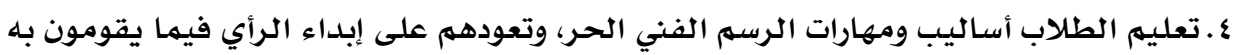

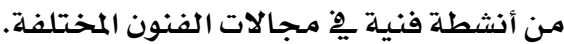

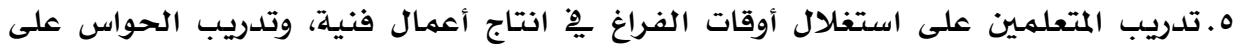

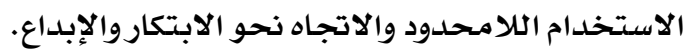

كما يمكن تلخيص الاهداف العامة للتربية الفنية كالآتي:

1. اكتساب المهارات الاساسية لأدراك عناصر الأعمال والمنتجات الفهات الفنية والتميز بينهما.

r. r. استشعار عظمه الخالق المتماثلة يِّ مظاهر الكون وأشكاله وأدواته.

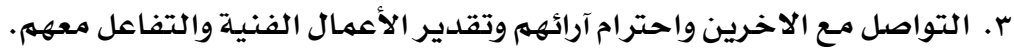

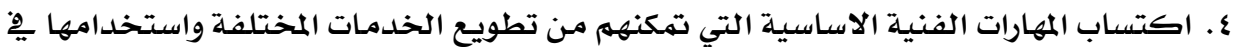

$$
\text { الانتاج الفني. }
$$

ه. التعبير الهادف عن شعورهم تجاه وطنهم وشعبهم وتراثهم الفني، والاعتزاز بـه من خلال

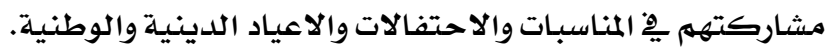

7. التعبير عن انفعالاتهم وافكارهم بلغه الفن البصرية وعناصرها؛ عن طريق مشاهداتهمه

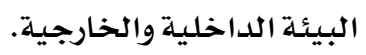

\section{دور المعلم والمدرسة في تنمية التذوق الفني والحس الجمالي عند الطلاب.}

أولا المعلم: يحتل المعلهم مـركزا أسـاسيا ِِِ أي نظام تعليمي لأنه من أهم العناصر الفاعلة

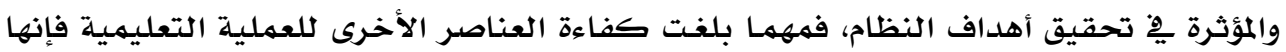

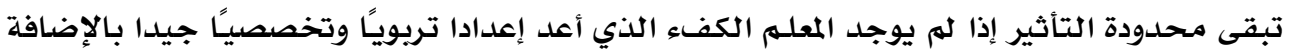




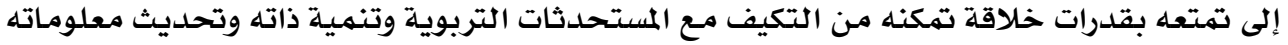

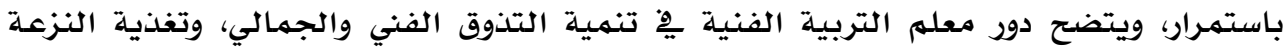

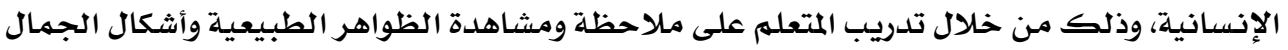

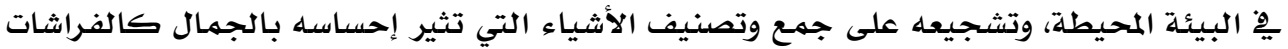

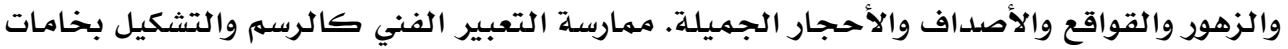

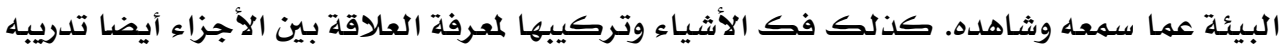
على كيفية استخدام أصابعه يِّا الرسه (Agar, 2018).

ثانيا المدرسة: أما عن دور المدرسة فيجب أن تشجع الطلاب على التذوق الفني من خلال

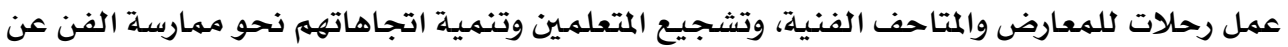

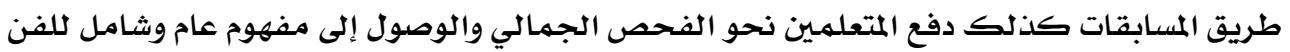

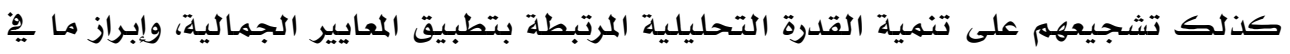

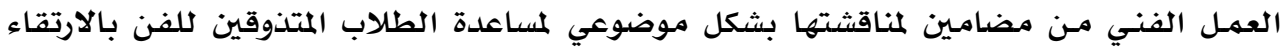

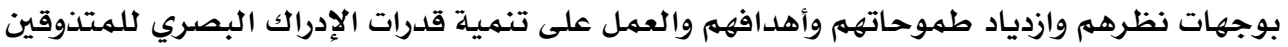

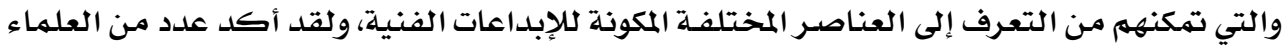

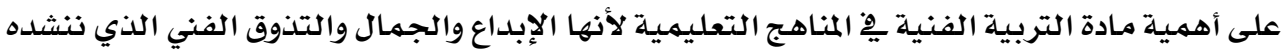

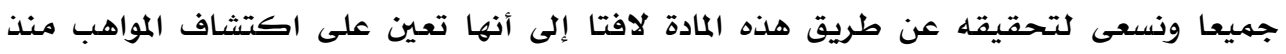
الصغر)(Duh, Cagran \& Huzjak, 2011).

\section{المحور الثاني: القصة:}

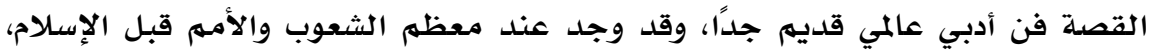

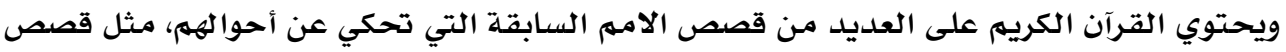

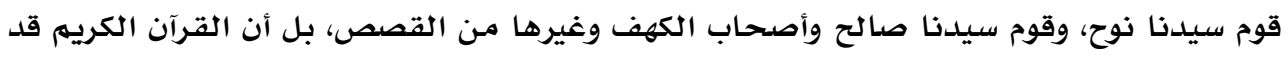

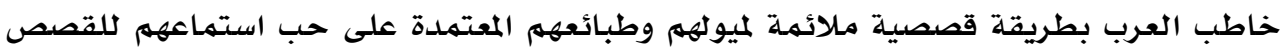

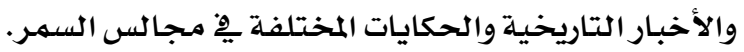

والقصص نوعان: منها ما هو خيالي ومنها ما هو حقيقي، فالقصة الخيالية تكون

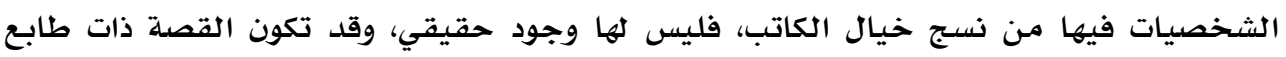

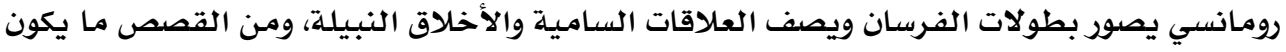

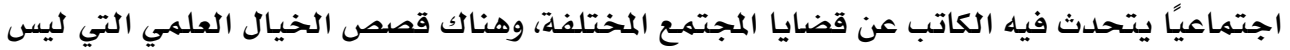

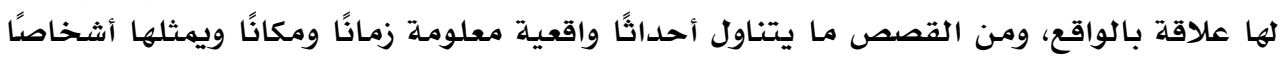

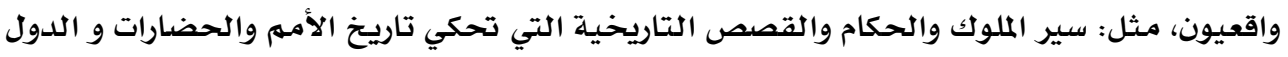
والبلدان (العموري، 19 بـr).

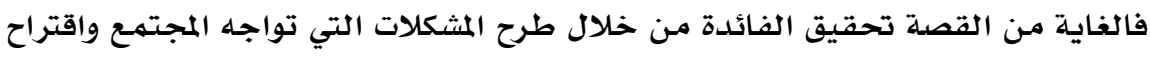

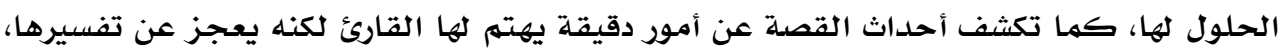


كما تحقق القصة التشويق والمتعـة من خلال طريقة بنائها وتسلسل أحداثها، والإبداع يِّ سرد إنها

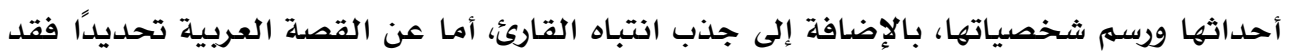

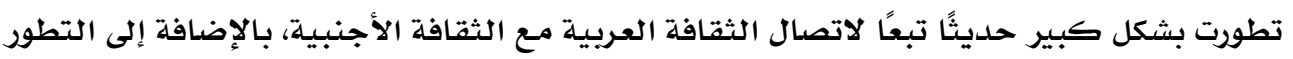

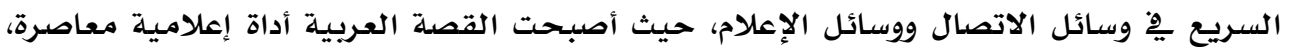

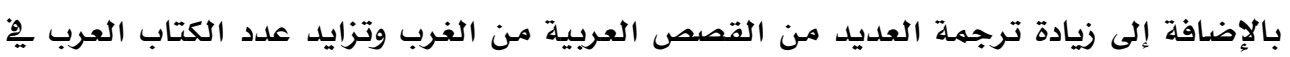

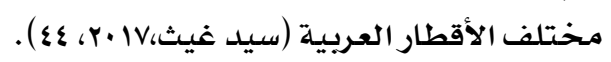

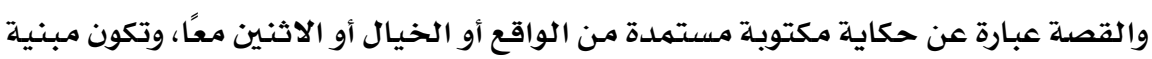

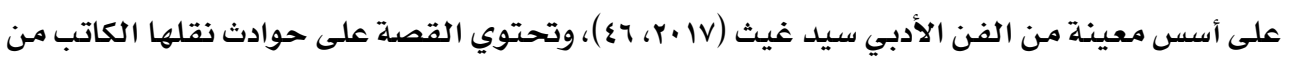

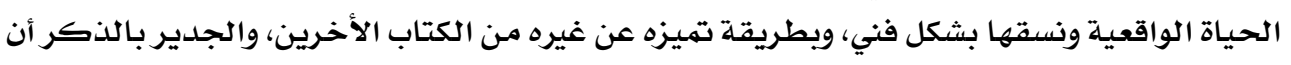

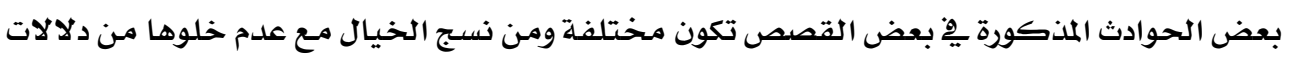

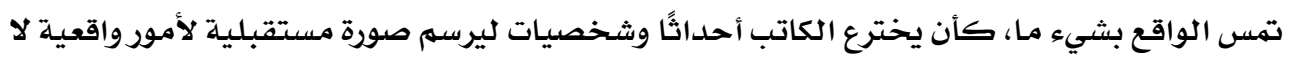

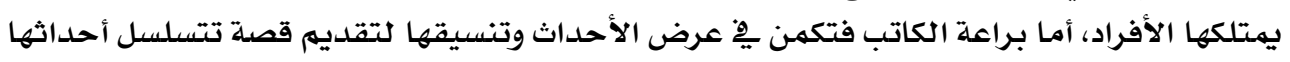

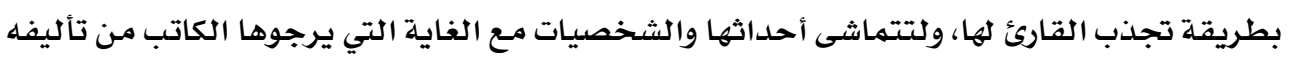

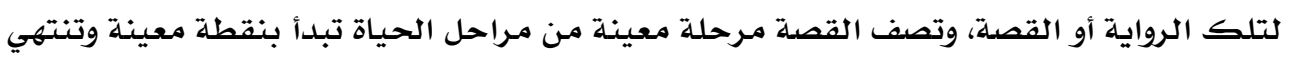

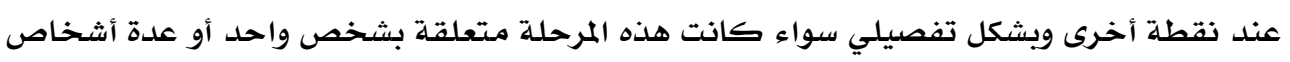

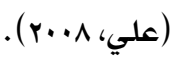

وعلى الرغم من الاختلافات الواقعة بين الكتاب والنقاد على تعريف القصدة إلا أنهم أجمعوا

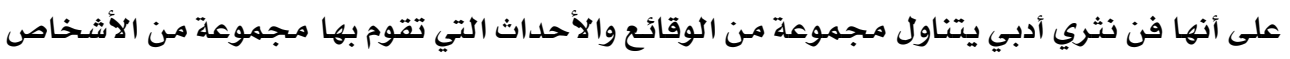

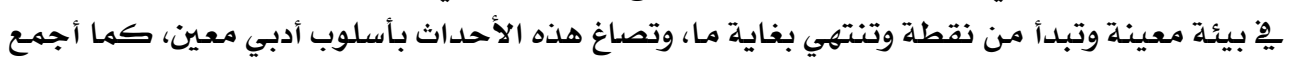

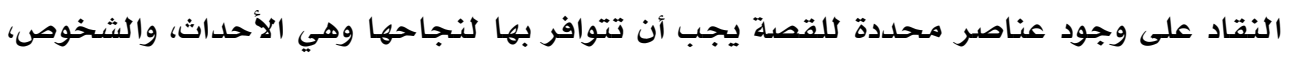

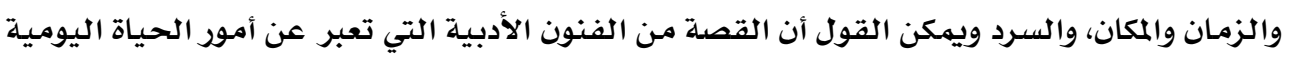

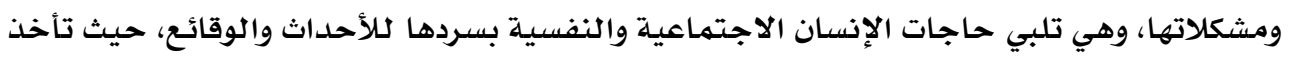

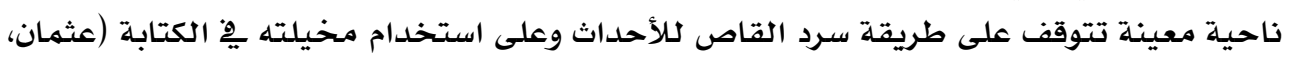

$(r \cdot 11$

\section{عناصر كتابة القصة:}

1- الفكرة: وهي الهدف الذي يريد الكاتب إيصاله للقارئ، ويهكن القول بأنها العبرة من القصة

$$
\text { التي يستفيد منها القارئ. }
$$

ץ- الحبكة: وهي مجموعة من الأحداث التي تلدور حول صلب الموضوع وتكون متسلسلة ومـرتبة

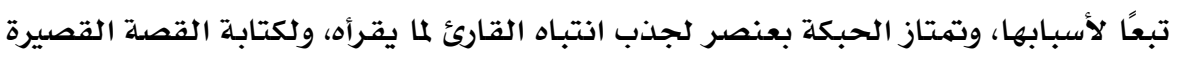

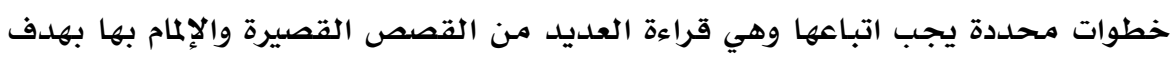

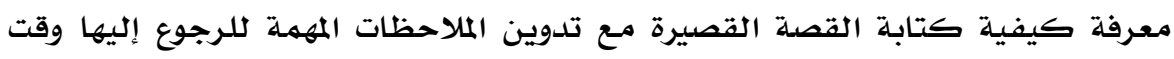

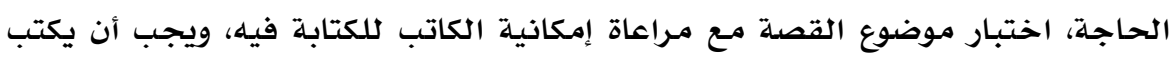


مجلة بحوث التربية النوعية - علدد بr - ميوليو r.rl

الكاتب مقدمة القصدة، ثم يتسلسل ِِّ الحوار والأحداث، والإلمام باللغة العربية وقواعدها

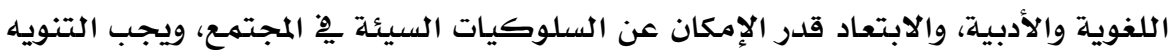

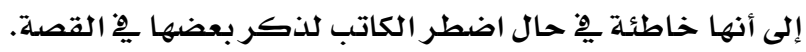

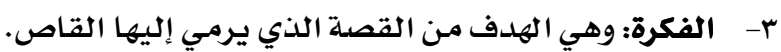

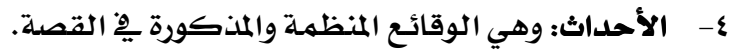

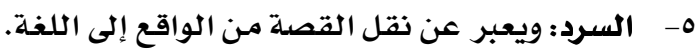

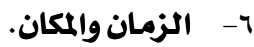

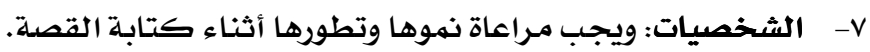

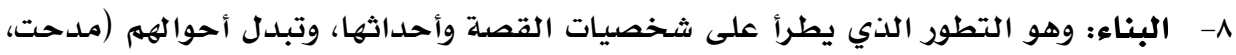

$$
\text { . }
$$

\section{أنواع القصص الموجهة للتلاميذ:}

تصنف القصص الموجهة إلى التلاميذ:

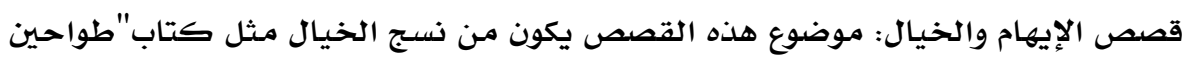

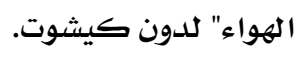

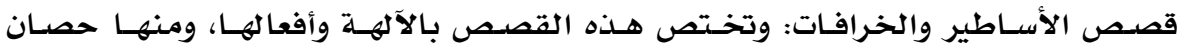

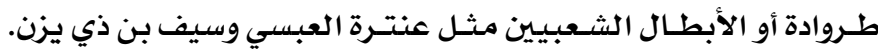

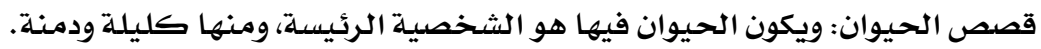

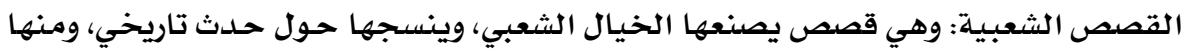

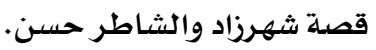
القصص التاريخية: وهي تدور حول الأبطال الذين أثروا ِِّ التاريخ، أو تركز على عادئ حادثة

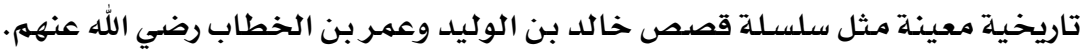

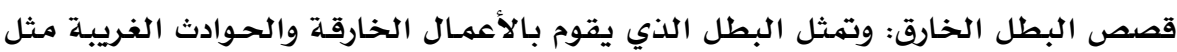
قصة هرقل. قصص البطولات الوطنية والدينية: وهي القصص التي تنهم عن الشعور بالكرامـة الوطنية

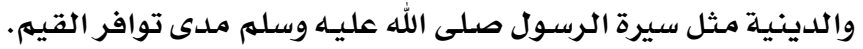

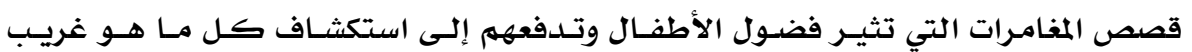

$$
\text { وغـامض مثـل رحسلات السـندباد. }
$$

القصص البوليسية ورجال الشرطة: وتدور حول المغامرات واستكشاف الأمور الغامضلة

$$
\text { والقبض على اللصوص والأثرار. }
$$

القصص الفكاهية: وهي قصص مرحة وطريفة من شأنها أن تخفف من التوتر الذي يعيشـه

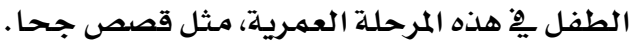

القصص العلمية وقصص المستقبل: وتهدف إلى إثارة الاهتمام بالعلهم وزيـادة الثقافة، وتنهمي

$$
\text { روح الإبـاع لدى الأطفال. }
$$




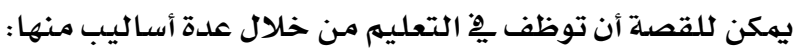

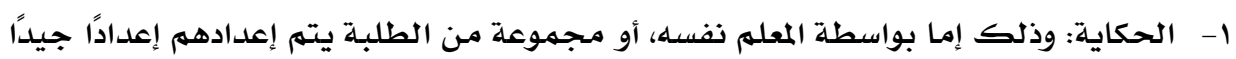

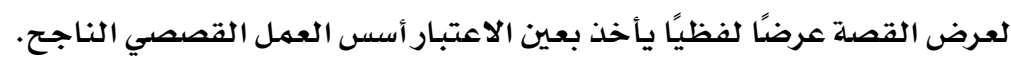

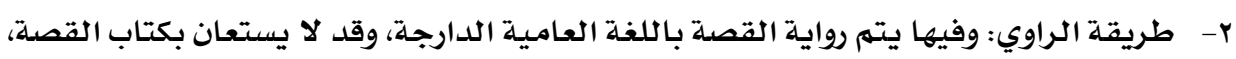

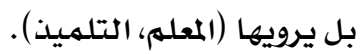

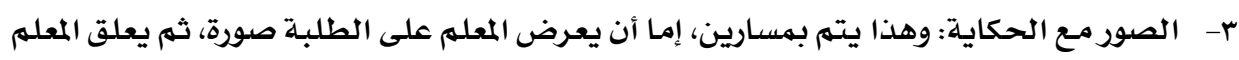

عليها بطريقة قصصية سردية، أو يترك الفرصدة للطلبة للتعليق عليها بالطريقة الطيقة أنفسها.

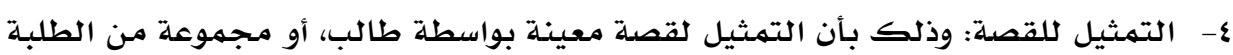

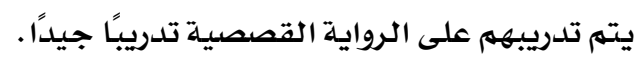

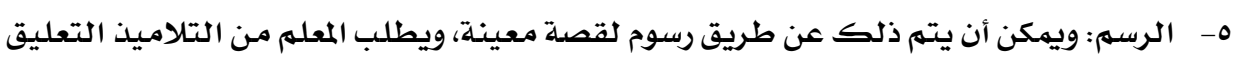

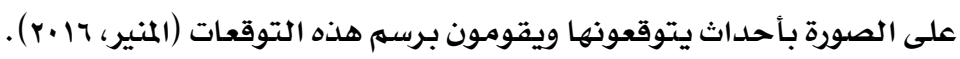

دور القصة التربوي:

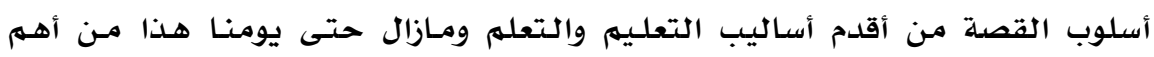

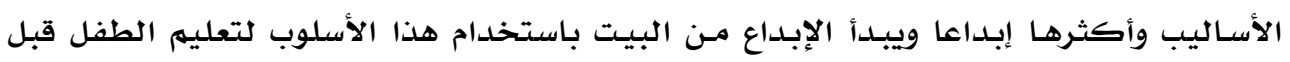

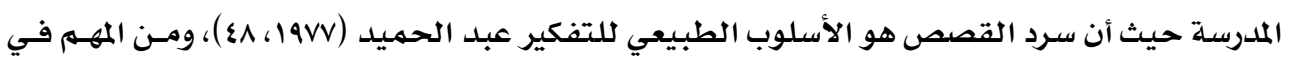

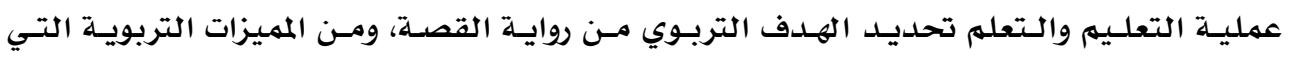

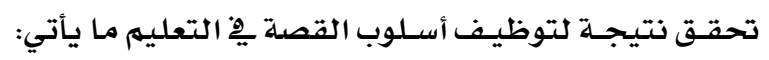

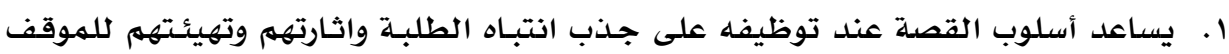

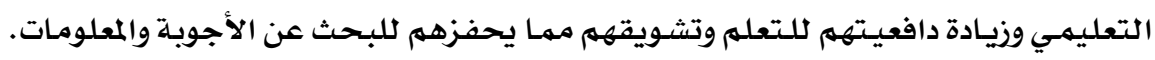

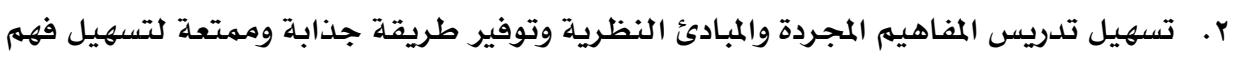

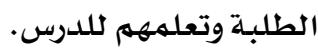
r. توثيق العلاقة بين المعلم والطلبة من خلال تواصل المعلم مـع الجميع ورواية القصص عن المعل الخبرات السابقة

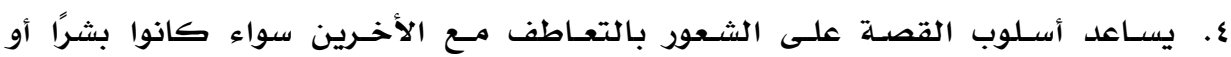

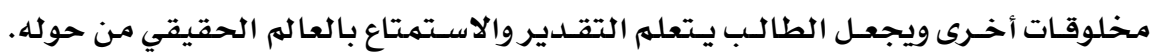

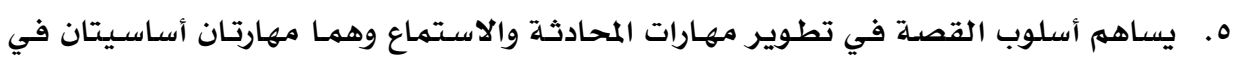

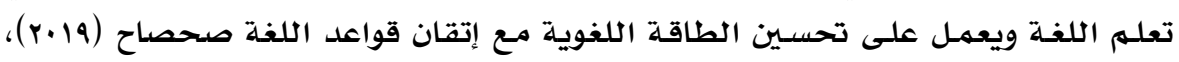

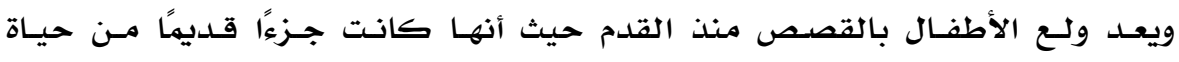

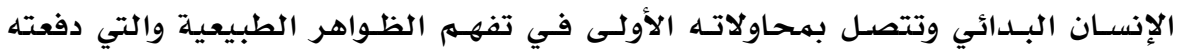

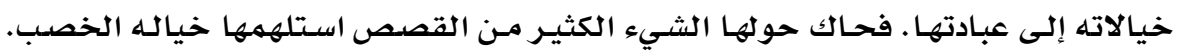




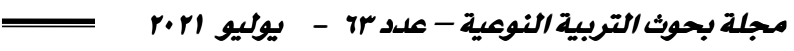

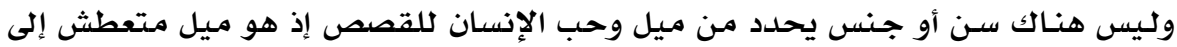
التراث الإنساني العالمي ذلك لان لان القصلة:

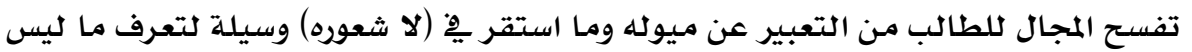

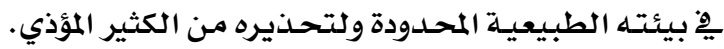
وسيلة نافعة إلى تسليتهم وإدخال السرور إلى نفوسهم وإثارة خيالهم وتشويقهم إلى التعليهم واجتذاب انتباههم. - طريقة ناجحة تستهويهـم إلى السلوك الحسن والأخلاق الطيبة بشكل غير مباشر.

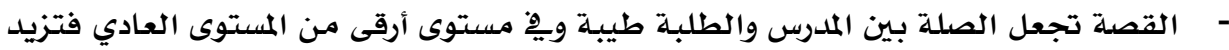

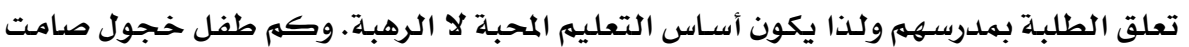

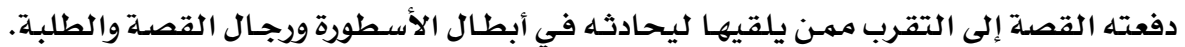

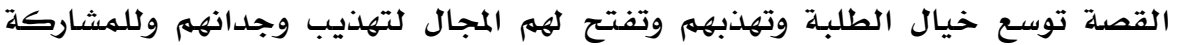
الوجدانية. - القصة وسيلة من الوسائل التعليمية (Al-Mansour, 2011).

التدريس بالقصة

يرى كل (2013) Handayani أن التدريس بالقصة يكون يِ أربع خطوات وهي: ا- التمهيد: ويتهم فيه استثارة انتباه المتعلمـين نحو موضوع القصة وتهيئتهم نفسيًا، وذهنيًا

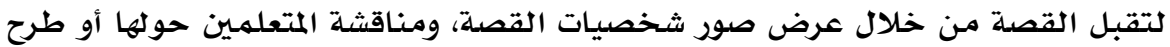

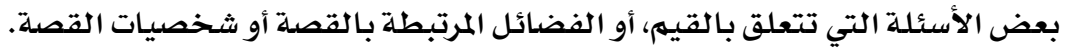
r - عرض القصدة: وذلك باستخدام طريقة من طرق السرد واستخدام الوسيلة المناسبة لها. r- ب- مناقشة القصة وتحليلها. ع- ريط القصدة بحياة المتعلم-ين.

\section{طريقة استخدام القصة:}

1- يجب أن يحدد المعلم أهداف الدرس بدقة. Y- يجب أن يختار المعلم قصدة مناسبة لموضوع الدرس فضلاً عن تحديد المدى الزمني للمناقشة. r- يجب تحديد المعلم مواضيع النقاش ليشرك الطلاب ِِّ إلقاء القصدة. ع- التنبؤ بالتوقعات الخاصدة بأحداثها كما ينبغي على المدرس ريط القصة بأهداف الدرس.

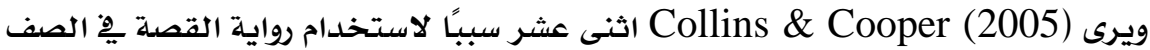

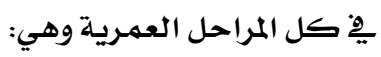

- تساعد يِّ تنمية الخيال والتمثيلات البصرية لدى الطلبة وهما مكونان هامان من مكونات

$$
\text { الإبداع. }
$$

- تسـاعد فِ تنمية تقدير اللغة وتذوق الجوانب الجمالية والفنية، والموسيقية فيها. 
تقدم الكلمات للطلبة ضمن سياق، مما يساعدهم على فهم الكلمات غير المألوفة وتوسعة

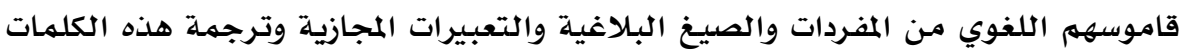

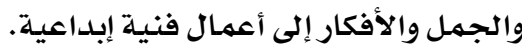

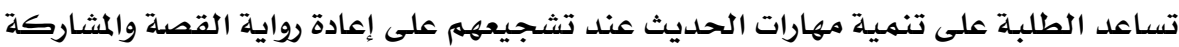

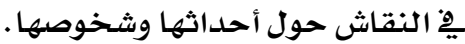

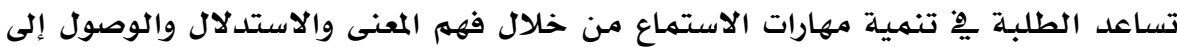

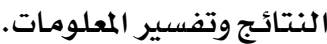
تساعد على تنمية التفاعل مـع الكبار على مستوى شخصئ.

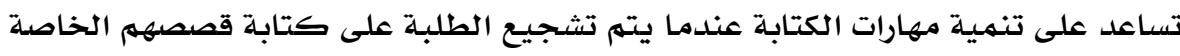
وترجمة القصص المسموعة إلى قصص مصورة.

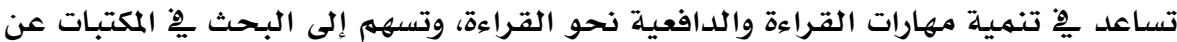

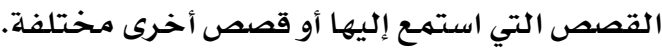

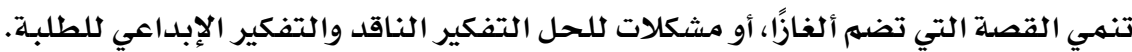
تسمـح للطلبة بمشاركة مشاعرهم.

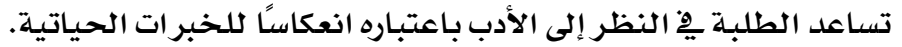

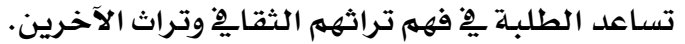

\section{المحور الثالث: الخيال الفنبي الفيد}

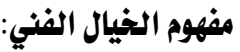

مجموعه من التطورات الذهنية الخالية القائمة على سلسله من الحقائق والمعارف والمبادئ

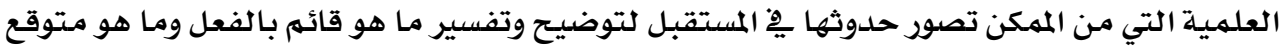

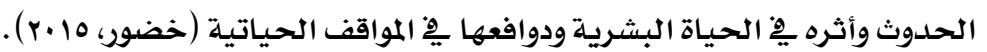

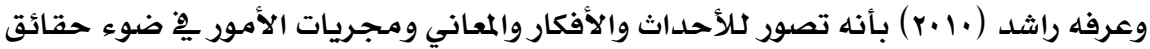

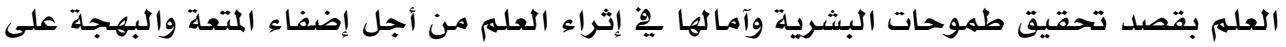
الحياة.

ويذكر (2003) أن الخبر ات الماضية التي مر بها المتعلمون سواء أكانت

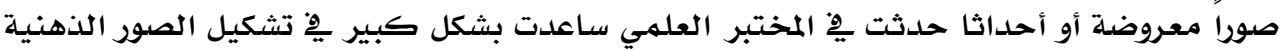

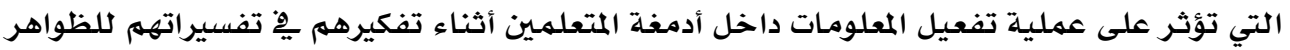

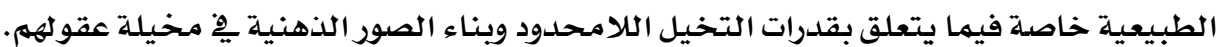
ويعرفه الباحث إجرائيًا بأنه المعالجة العقلية للصور والأشكال والرسوم والأشخاص والئل

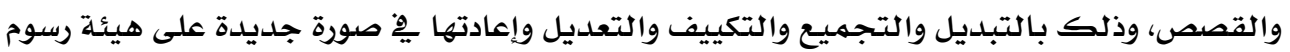

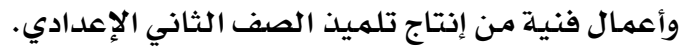




\section{أهداف الخيال العلمي: - n}

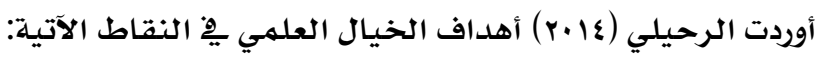
ا- تعليم الحقائق والمعارف والمفاهيم العلمية بأسلوب شيق وممتع يزيل جفاء وصعوبة المادة الدراسية.

r- مساعدة الطلاب على التفاعل مـع تكنولوجيا الحاضر والمستقبل.

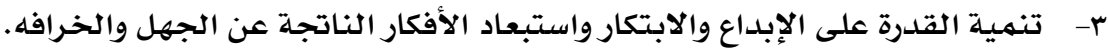

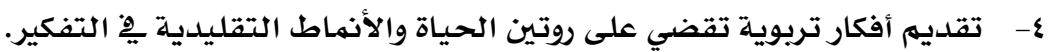

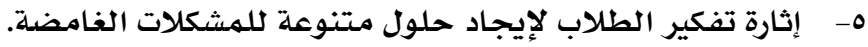

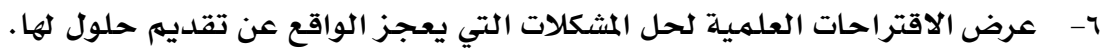

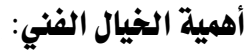
أهمية الخيال تقترب مهام الخيال من فعالية الإلهام التي تقدم حلونًا منتجة جدًا ولهذا فهي نافعة يف أغلب الأحيان إذا كانت لا تؤدي إلى مفهومـين: 1- التعامل مع الخيال الغرائزي فقط الذي يترجم بطائر الخيال.

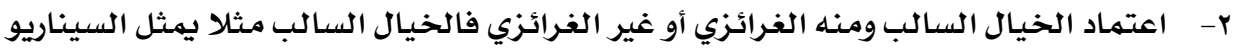

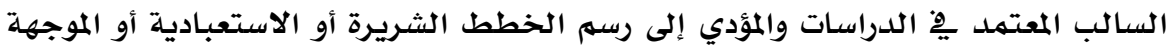

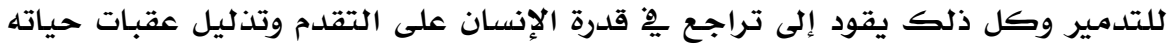

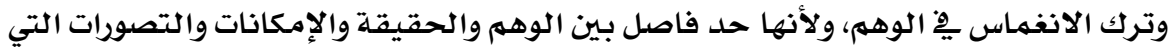

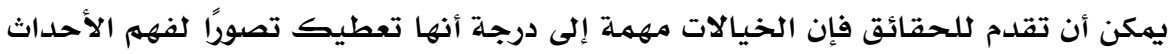

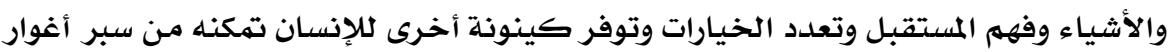

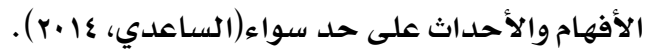
محفزات الخيال العلمي

أوضح كل من (الشبر اوي، عا.ب ؛ أبو سعيدي، البلوشي، 19 ·r) أن الناس يعايشون الخيال مِّ ثلاث صور.

1- بصورة عفوية تلقائية: من أفضل الأمثلة على ذلك عندما تتخيل صورة ذهنية لمذيع في

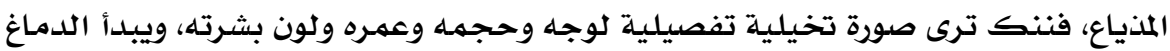

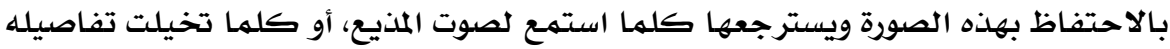

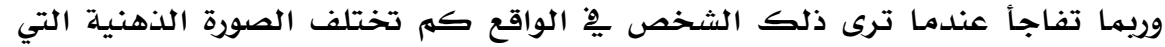

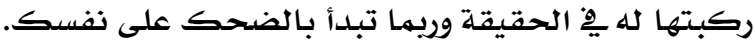
r- عن طريق التحفيز والاستثارة: ويحدث ذلك عندما تتعرض لمثير مدهش، حتى تستثير

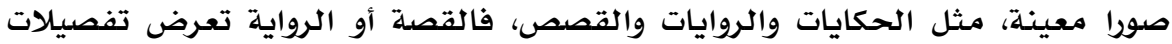
دقيقة تحفز الدماغ على تكوين صور ذهنية الحئل مات يستمـع لله. 
r- التوجيه الذاتي الداخلي لتوليد الأفكار الإبلداعية: يحدث التوجيه الذاتي الداخلي، عندما

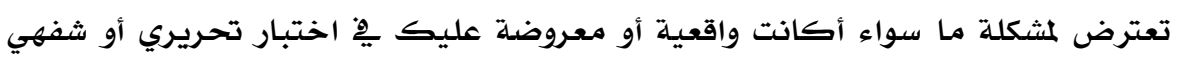

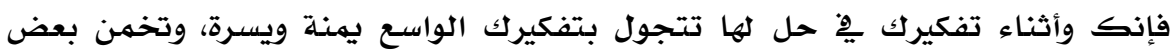

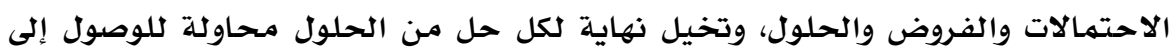

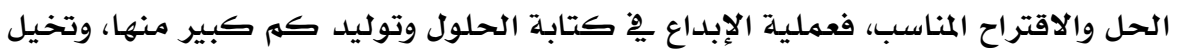

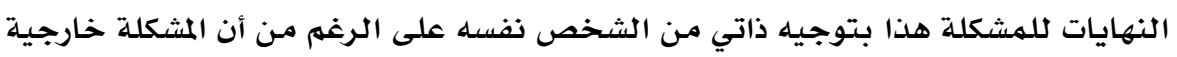

$$
\text { كمثير. }
$$

أنواع الخيال الفني:

صنف عالم النفس الفرنسي ريبوت Ribot/الخيال إلى ثهانية أنواع.

- الخيال التشكيلي Plastic Imagination ويقوم على أساس الصور.

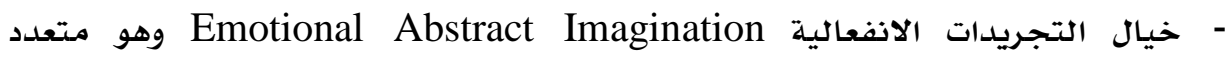

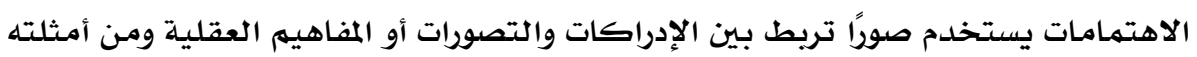

$$
\text { اللوحات الانطباعية والموسيقى الرمزية. }
$$

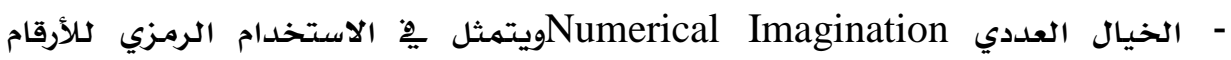
ودلالاتها كما يِّ الرياضيات والأساطير والدين.

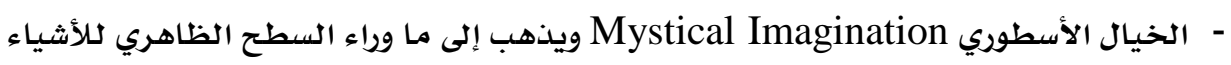
ويدخل إلى أعماق الخبرة الوجودية الإنسانية. - الخيال العلمي Scientific Imagination ويقوم على ثلاث أنشطة أساسية العية هي: الملاحظة والفرض والتحقق، ويشمل الخيال يِّ مجالات الهندسلة والكيمياء والفيزياء.

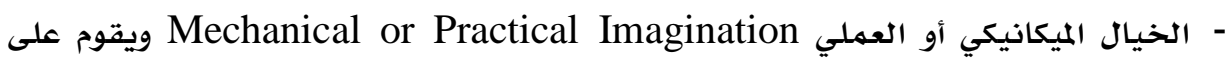

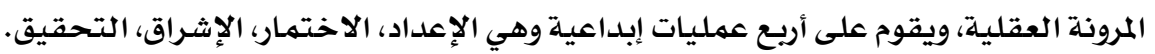

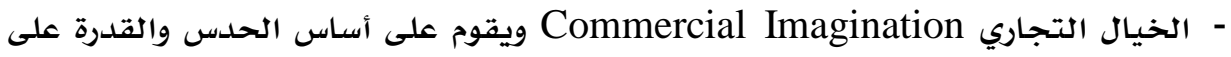

$$
\text { وضع الافتراضات حول تذبذبات السوق والاقتصاد. }
$$

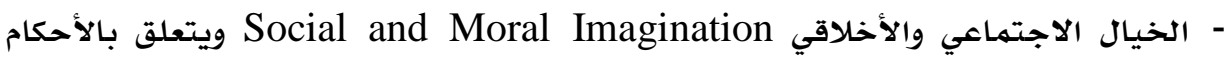
الأخلاقية والاجتماعية وهي أحكام مكتسبة من الاجية البيئة، وهو أقرب الى خيال الفلاسفة

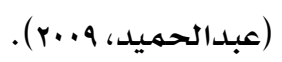

ويركز البحث الحالي على تنمية الخيال بوجها عام لديلى تلاميذ الديد الصف الثاني الإعدادي

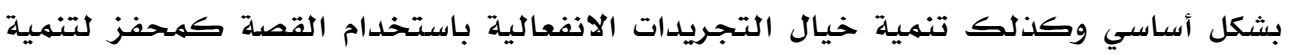

$$
\text { الخيال الفني لدى تلاميذ الصف الثي الثاني الإعدادي. }
$$




\section{الدراسات السابقة}

الدراسات العربية:

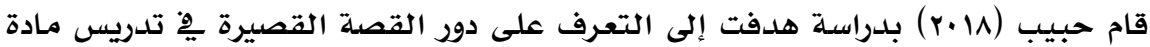

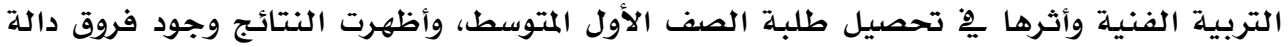

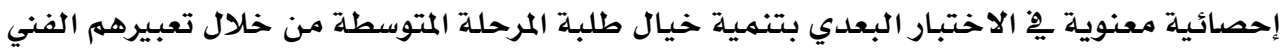

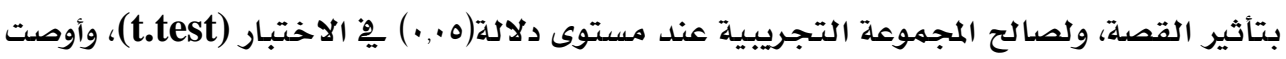

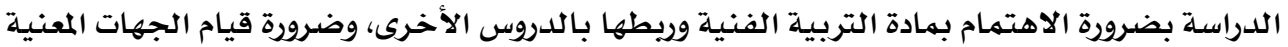

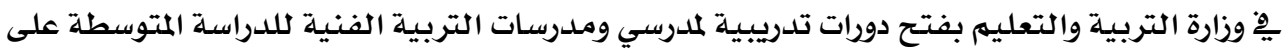
إتقان اللغة العربية والابتعاد عن اللهجة التئة العامية.

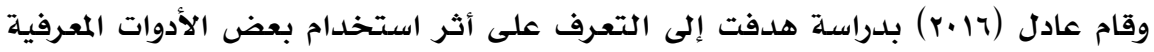

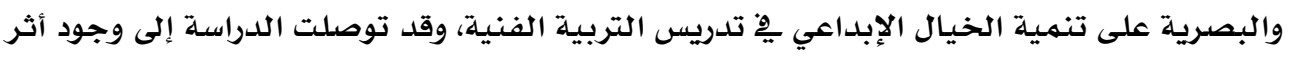
كبير لكلأدوات المعرفية والبصرية يْية تنمية الخيال الإبداعي يْ تدريس التربية الفنية لدى عينة الدراسـة.

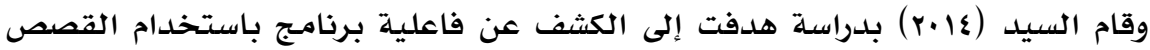

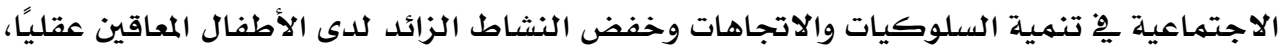

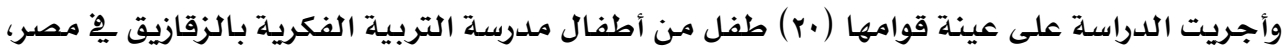

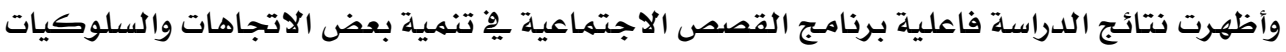

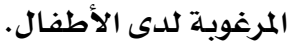

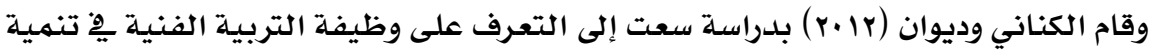

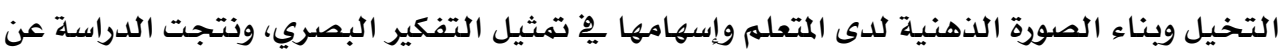

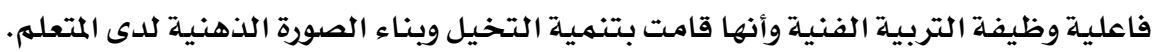

\section{اللدراسات الأجنبية.}

قام كل من (2009) Bickmore, Thompson, Grandy and Tomlin بدراسـة علهم رواية القصص كأسلوب لتدريس العلوم الطبيعية والعلهم ِِّ مواجهة الدين، وتكومن عينة الدراسة

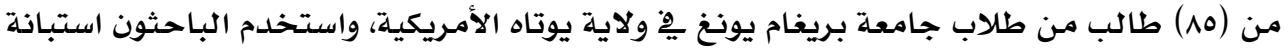

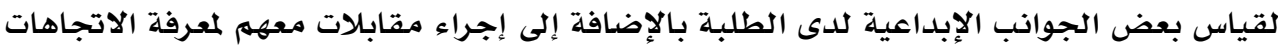

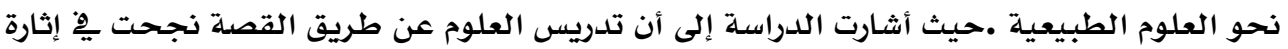

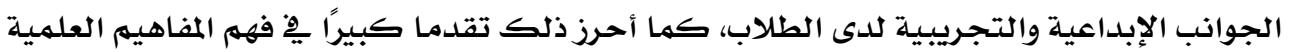

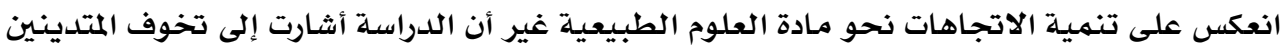

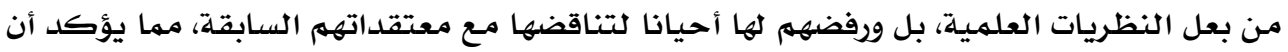

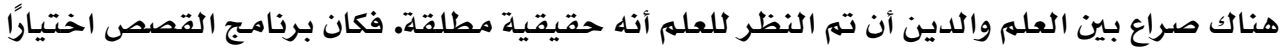
جيدًا لأولئك القلقين حول المحتوى العلمي وطبيعته وبذلك وفر تدريس العلوم عبر القصص إطارا 
واضحا لفهم العلهم بطريقة صحيحة، مما يساعد ِِّ التفاعل الإيجابي بين العلهم والدين على أن يتم

إعداد القصص بعناية.

وقام Upadhyaya (2005) بدراسة هدفت إلى فحص تأثير استخدام الخيال ِِّ تنمية

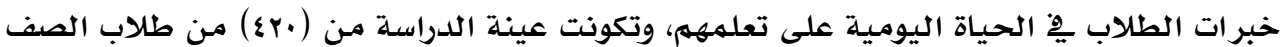

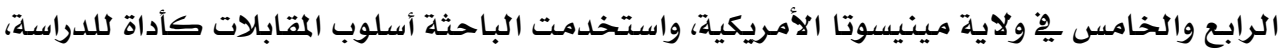

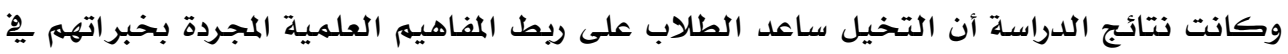

$$
\text { الحياة اليومية، وزاد التحصيل الدراسي لديهم. }
$$

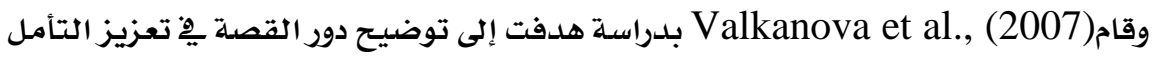

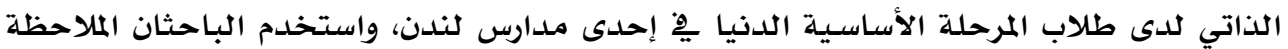

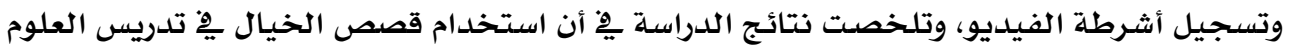

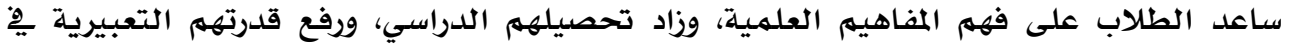

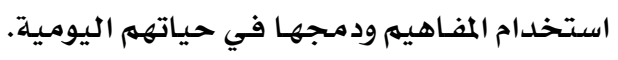
التعقيب على اللدراسات السابقة:

ِِّ ضوء الدراسات السابقة تتضح فاعلية استخدام القصة على التدريس وتأثيراتها

$$
\text { الإيجابية على العديد من المتغيرات: }
$$

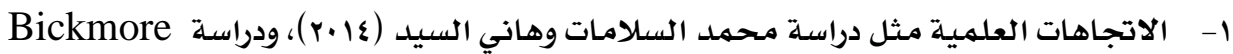

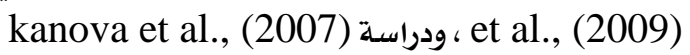

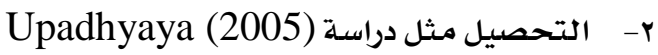

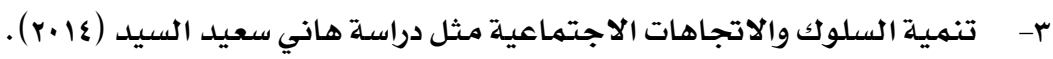
ومن الدراسـات التي اهتمت بالخيال لدى المتحلمين:

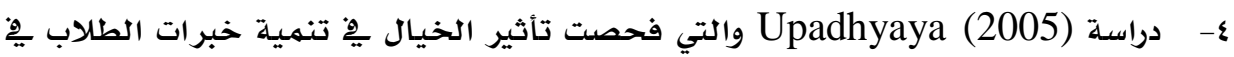
الحياة اليومية.

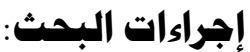

\section{أولاً. أداة جمع البيانات (قائمة مهارات الخيال الفني اللازمة لتلاميذ الصف الثاني المتوسط)}

تطلب البحث الحالي تحديد مهارات الخيال الفني المناسبة لتلاميذ الصف الثاني المتوسط،

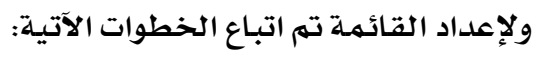

ا ـ تحديد الهدف من القائمة: وهو تعرف مهارات الخيال الفني اللازمة لتلاميذ الصف الثاني

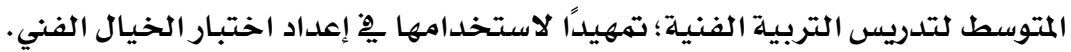

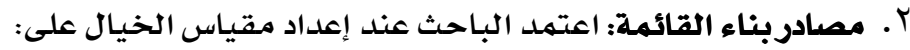

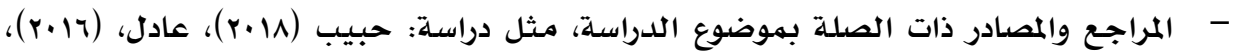

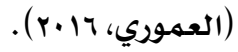




$$
\text { - البحوث والدراسات التي تناولت مهارات الخيال الفني. }
$$

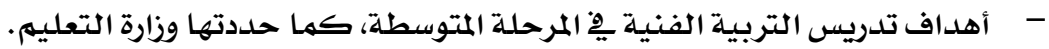

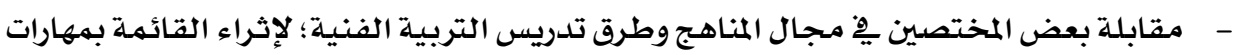

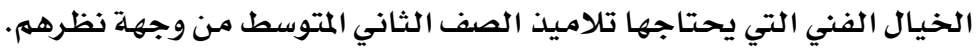
مقابلة بعض معلمي طلاب الصف الثاني المتوسط؛ وذلك للإفادة من آرائهم ِِّ مهارات

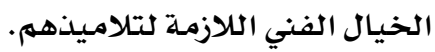

\section{r. إعداد القائمة مِِصورتها الأولية:}

تم التوصل إلى عدد من المهارات الرئيسة، والمهارات الفرعية الأدائية وتضمنت قائمة التهـة المهارات

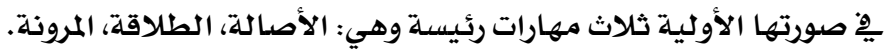

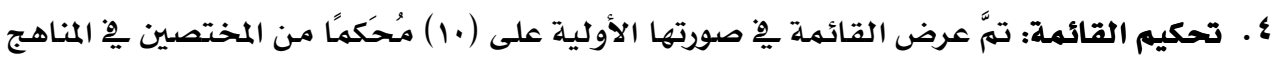

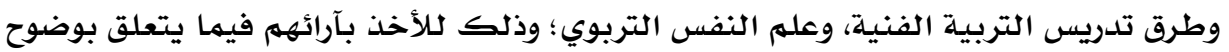

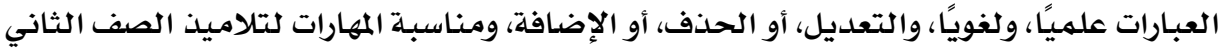

الإعدادي.

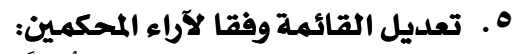

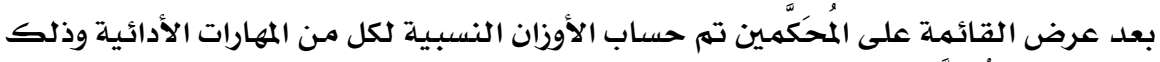

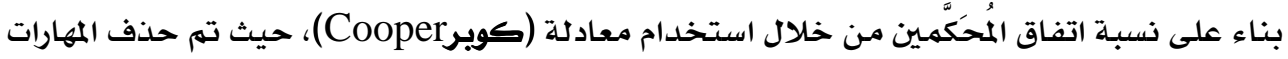

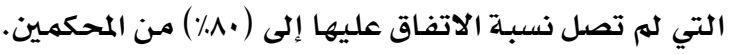

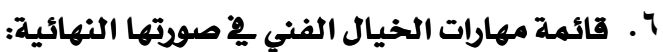

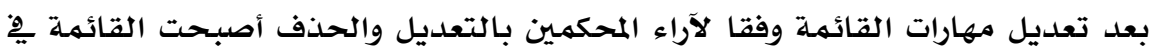
صورتها النهائية تحتوي على أريع مهارات رئيسة وتسـع مهارات فرعية أداءئ أدئية. ويذلك يكون قد تمت الإجابة عن السؤال الأول من أسئلة البحث، ونصهه" ما مهارات الخيال

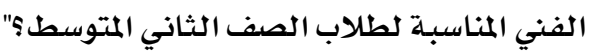

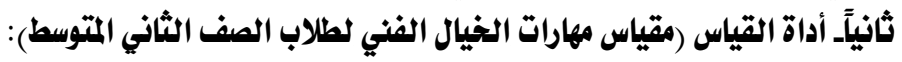
أعد الباحث مقياسًا لقياس مهارات الخيال الفني لطلاب الصف الثاني المتوسط، من خلال

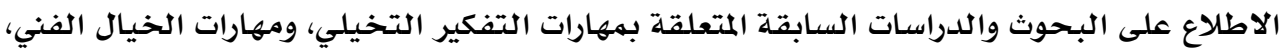

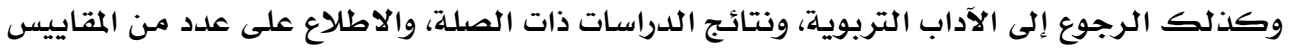

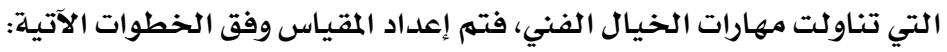
أ. الهدف من المقياس: هدف المقياس إلى قياس مدى توافر مهارات الخيال الفني لطلاب الصف الثاني المتوسط. ب. تحديد محتوى المقياس: تضمن المقياس مجموعة تمن من الأسئلة التي تقيس مهارات الخيال الفني

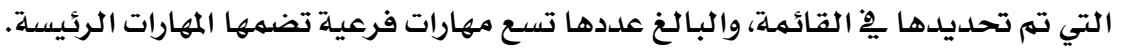


ت.حساب صدق المقياس:

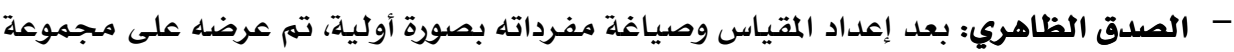

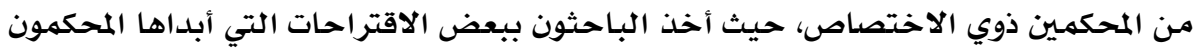

$$
\text { لتوافقها مع أهداف البحثث. }
$$

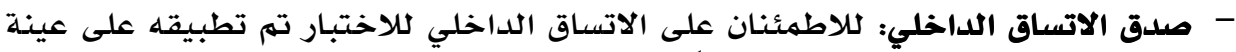

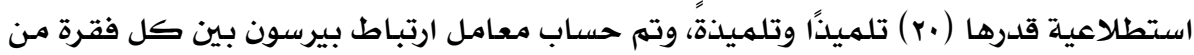

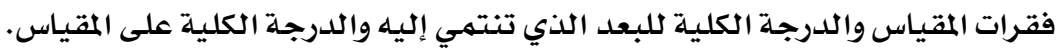

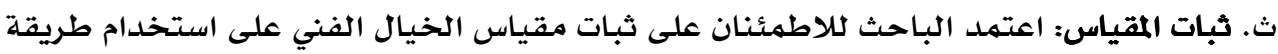

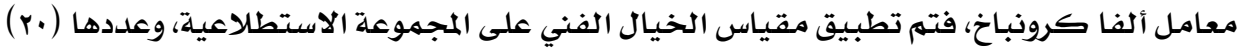

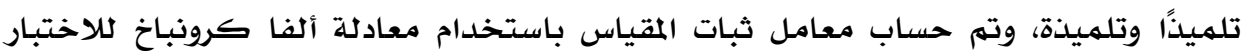
وأبعاده. والصورة النهائية للمقياس: بعد انتهاء الإجراءات الإحصائية للاختبار أصبح المقياس

$$
\begin{aligned}
& \text { بصورته النهائية صالحًا للتطبيق. } \\
& \text { ثانيا- تجربة البحث: } \\
& \text { 1- اختيار مجموعة البحث: }
\end{aligned}
$$

تم تطبيق تجرية البحث على تلاميذ الصف الثاني المتوسط، وذلك بعد الانتهاء من إعداد

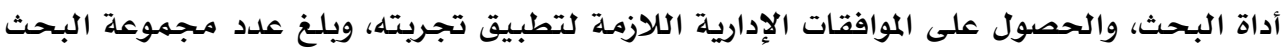

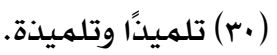

\section{r- ت تحديد الهدف من التجرية:}

هدف البحث الحالي إلى تنمية مهارات الخيال الفني المناسبة لتلاميذ الصف الثاني

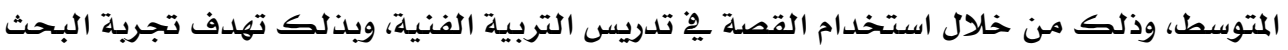

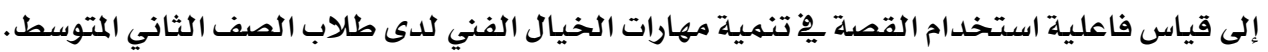

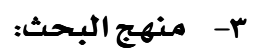
اتبع الباحث ِِّ تطبيق تجرية البحث على المنهج شبه التجريبي ذي المجموعة الواحدة،

$$
\begin{aligned}
& \text { نظرًا لمناسبة هذا التصميم لمتغيرات البحث. } \\
& \text { ع- اختيار مجموعة البحث: } \\
& \text { ه- التطبيق القبلي لمقياس مهارات الخيال الفني: }
\end{aligned}
$$

تم تطبيق المقياس على مجموعة البحث قبليًا بهدف الوقوف على مستوى أفراد المجموعة

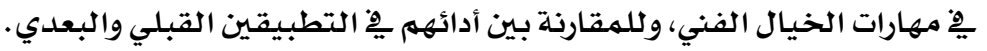
ז- التطبيق البعدي للمقياس: 


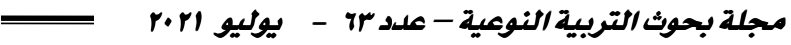

تم تطبيق مقياس الخيال الفني بعديًا على مجموعة البحث؛ حتى تتم المقارنة بين نتائج

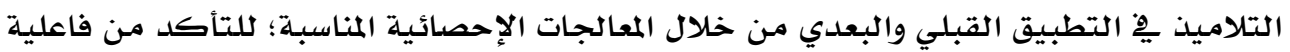

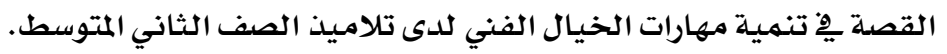

\section{نتائج البحث وتفسيرها وهناقشتها:}

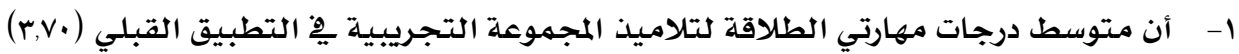

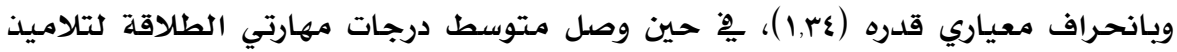

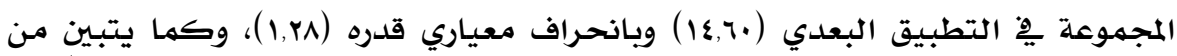

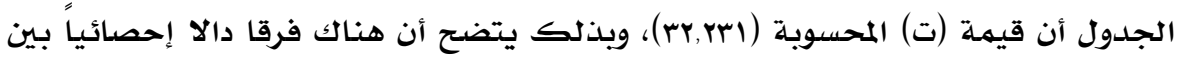

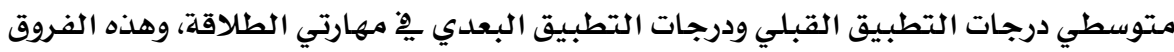

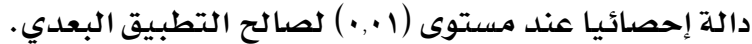

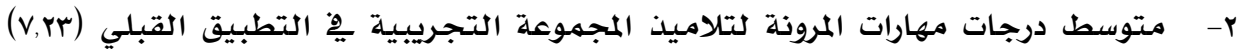

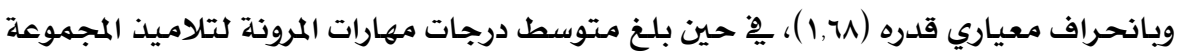

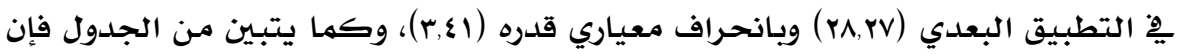

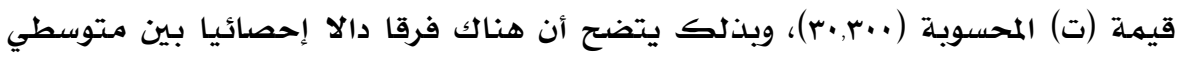

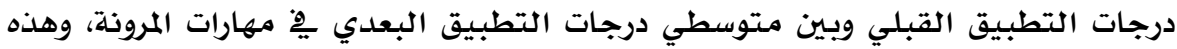

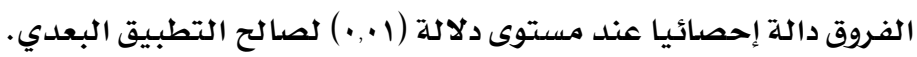

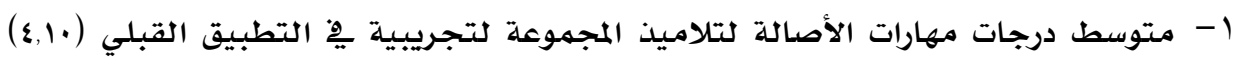

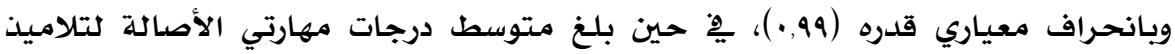

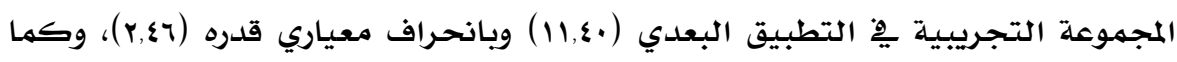

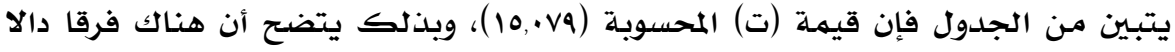

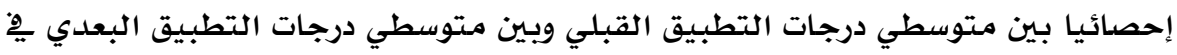

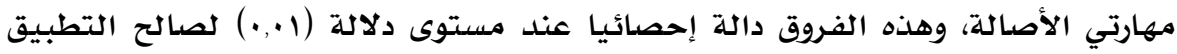
البعدي.

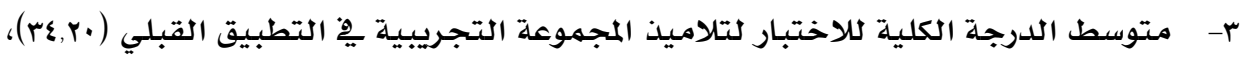

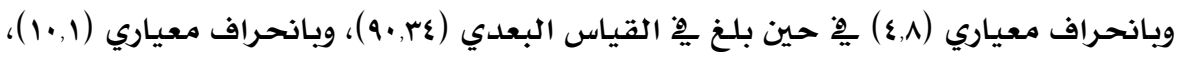

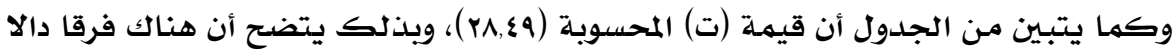

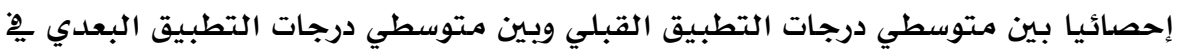

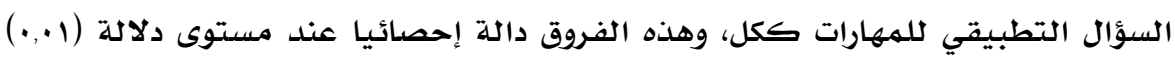
لصالح التطبيق البعدي. ولإجابة عن السؤال الثاني من سؤالي البحث، ونصه: "ما أثر استخدام القصة يِّ تدريس

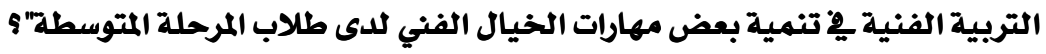




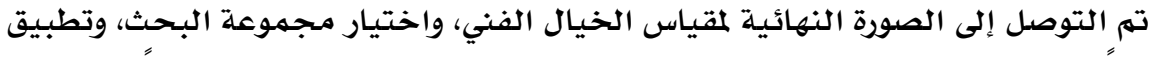

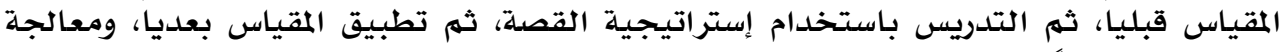

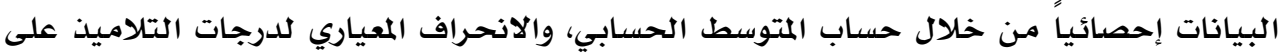

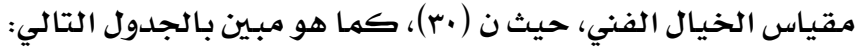

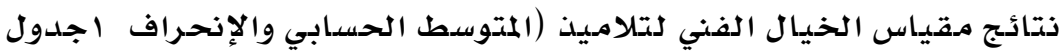

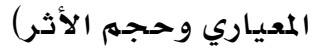

\begin{tabular}{|c|c|c|c|c|c|c|c|c|}
\hline \multirow{2}{*}{ حجم الأثرى } & \multirow{2}{*}{ قيمة حجم الأثر } & \multirow{2}{*}{ مستوى } & \multirow{2}{*}{ قيمة ت } & \multicolumn{2}{|c|}{ القياس البعدي } & \multicolumn{2}{|c|}{ القياس القبلي } & \multirow{2}{*}{ المهارات } \\
\hline & & & & $\varepsilon$ & P & $\varepsilon$ & P & \\
\hline كبير & $\cdot, 9 v$ & $\cdot, \cdot \cdot 1$ & rr, rrI & $1, \mathrm{rA}$ & $1 \xi, 7$. & $1, r \xi$ & $r, v$. & الطلاقة \\
\hline كبير & •, 9v & $\cdot, \cdot \cdot 1$ & $r \cdot, r \cdot \cdot$ & $r, \$ 1$ & $r A, Y V$ & 1,71 & $\mathrm{~V}, \mathrm{rr}$ & المرونة \\
\hline كبير & $\cdot, \wedge 9$ & $\cdot, \cdot \cdot 1$ & $10, \cdot v 9$ & $r,\{Y$ & $11, \xi$. & $\cdot, 99$ & $\$, 1$. & الأصالة \\
\hline كبير & $\cdot, 97$ & $\bullet,+1$ & $\mathrm{rA}, \leqslant 90$ & $1 \cdot, \cdot 1$ & $9 \cdot, \xi 4$ & $\xi, \bullet \wedge$ & $r \xi, r \cdot$ & اللدرجة الكلية \\
\hline
\end{tabular}

ويتضح من خلال الجدول السابق أن هناك فرقا دالا إحصائيا عند مستوى دلالة ( +.. • بين

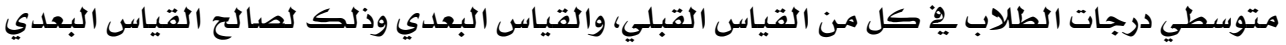

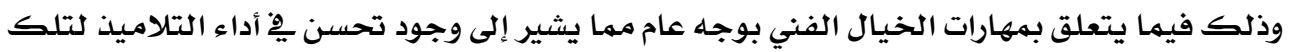

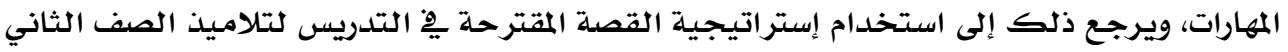

Exploration of the Results :ثلنيا: هناقشة النتائجة

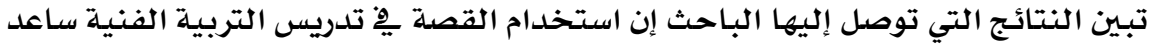
هِِ تنمية مهارات الخيال الفني لدى طلاب الصف الثاني المتوسط بالمرحلة المتوسطة مقارنة بالطريقة

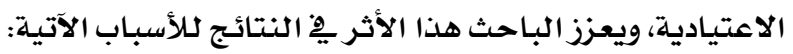
ا- إن القصة تتمتع بخطوات منظمة مهمة إذ تمنح الطلبة القدرة على تبادل الخبر ات فيما بينهم وتمنحهم ثقة أكبر بالمثاركة والتعلم ما يزيد قدرتهم على تعلهم مهارات الخيال الفني.

r- إن هذه القصة تراعي الفروق الفردية لكل تلميذ وتحثهم على المشاركة الفاعلة.

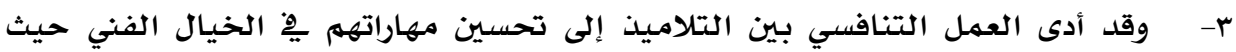

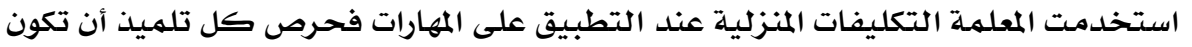

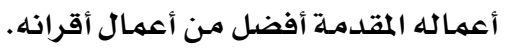

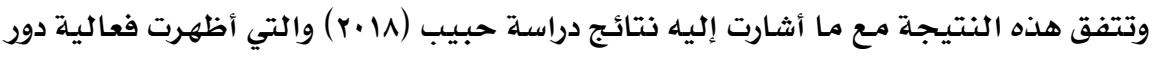

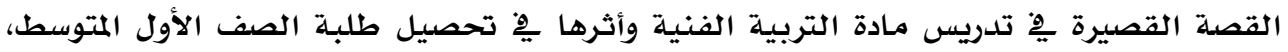




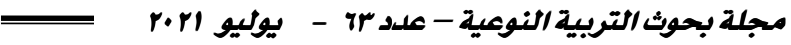

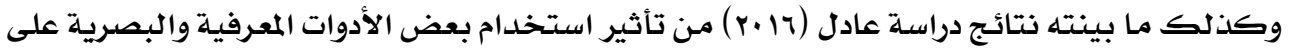

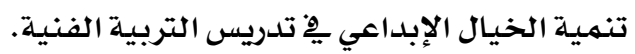

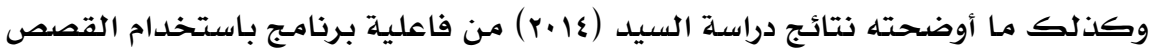

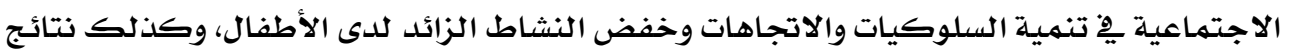

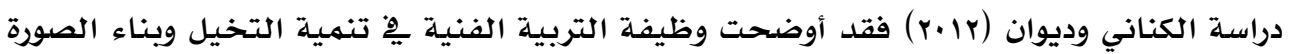
الذهنية لدى المتعلم وإسهامها يِّ تمثيل التفكير البصري.

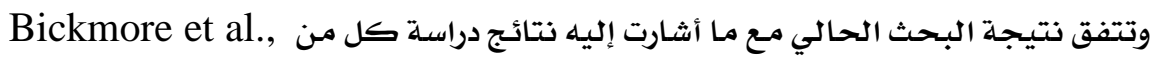

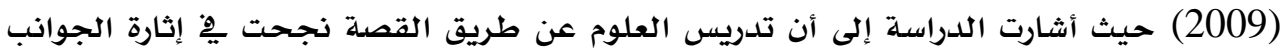

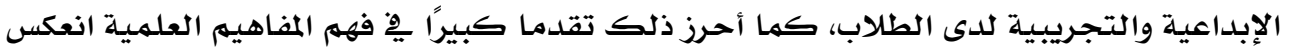
على تنمية الاتجاهات نحو مـادة العلوم الطبيعية.

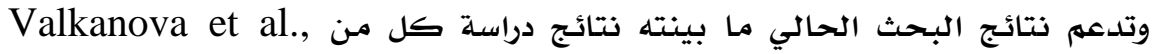

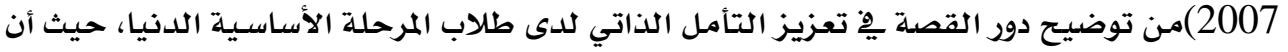

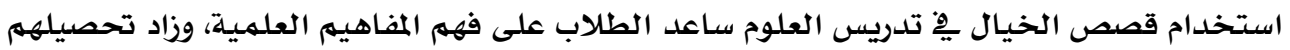

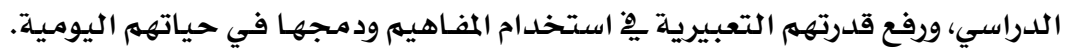
ثالثا: توصيات البحث Recommendation: مِِ ضوء النتائج تم التوصل إليها يوصي الباحث بما يأتي: 1 - ضرورة التنوع يِّ استخدام طرائق تدريس مختلفة وحلديثة، ومن بينها الإستراتيجية الحالية

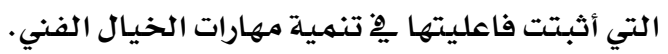

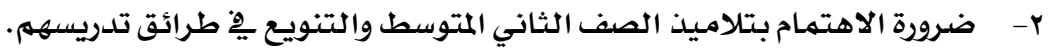

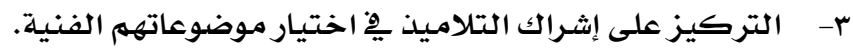

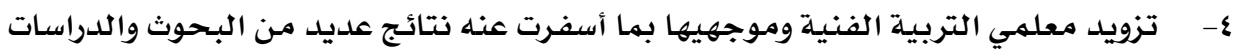

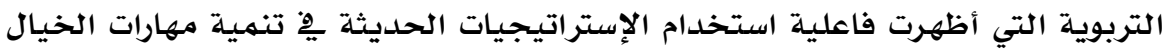

رابعا: هقترحات بمثية: Suggestions

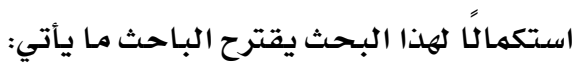
1- فاعلية برنامـج تدريبي قائم على استخدام القصلة ِِّنتمية الانتاج الفني لدى تلاميذ المرحلة المتوسطة. ץ- فعالية برنامج تلدريبي للتربية الفنية قائم على القصلة ِِّ تنمية مهارات الفن التشكيلي

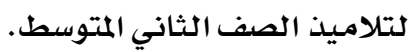

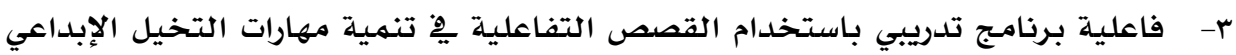
لتلاميذ الصف الثاني المتوسط. 


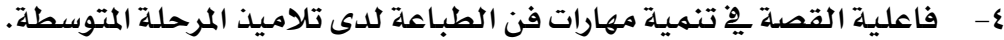
هـ - نمدجـة العلاقات السببيـة بين الخيال الفني والتخيل الإبـاعي ومهارات التفكير الإبـاعي.

\section{قائمة المراجع}

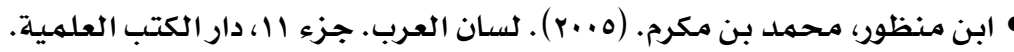
• أبوسعيدي، عبدالله والبلوشي، سليمان. (19 •r) . طرائق تدريس العلوم مفاهيهم وتطبيقات علمية. عمان: دار المسيرة.

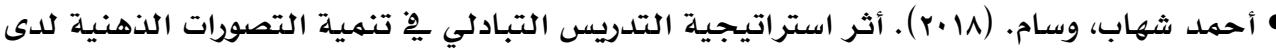
طلبـة قسمى التربية الفنية، مجلـة مـركز دراسـات الكوفة، (10). • بريت، ر، ل. (19v9) ) التصور والخيال. ترجمـة: عبدالواحد لؤلؤة، بغداد: دار الرشيد.

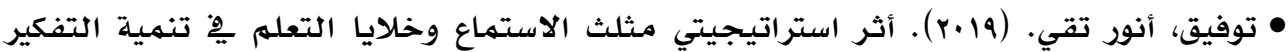
التخيلي لدى طلاب الصف الثاني المتوسط ودافعيتهم نحو مادة الأدب. المجلة العربية للعلوم

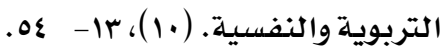

• جابر، عبد الحميد. (19VV) ). علم النفس التربوي. القاهرة: دار النهضة العربية.

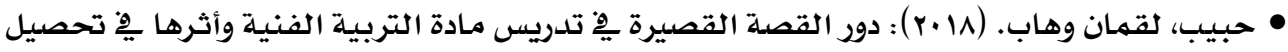
طلبة الصف الأول المتوسط. رسالة مـاجستير غير منشورة، كلية التربية، عمان.

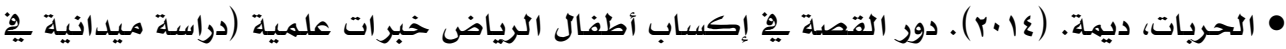

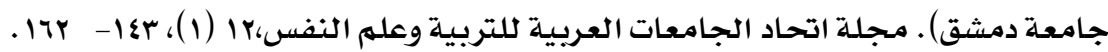

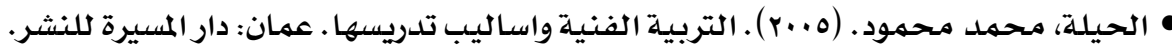
• خضور، خلود. (10 •r). فاعلية برنامـج حاسوبي قائمر على الخيال العلمي يْ تنميـة بعض المفاهيم العلميلة لدى أطفال الروضـة. رسالة ماجستير غير منشورة. كلية التربية، جامعة دمشق. • دحلان، براعم. (7 (r) ). فاعلية توظيف القصص الرقمية يخ تنمية مهارات حل المسائل اللفظية الرياضية لدى تلامدة الصف الثالث الأسساس بغزة. رسالة ماجستير غير منشورة، كلية التربية، الجـامعة الإسـلاميـة.

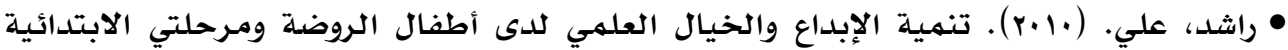
والإعدادية. عمان: ديبونو للطباعة والنشر. • الرحيلي، أمـينـة. (عا •r) . فاعلية برنامـج مقترح قائم على بعض أدوات الجيل الثاني للويب لإثراء

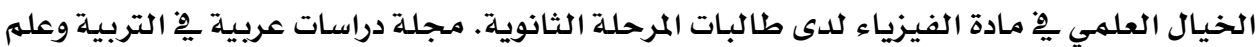

$$
\text { النفس، 1(01)، }
$$

• رضوان، مـرفت محمد ( •(+r). دليل المعلم كتاب التربية الفنية. الامـارات العربية: وزارة التعليهم 


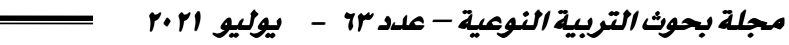

• الساعدي، رحيه. (§ إr): فلسفة الخيال قراءة ِِّ محرك الإبداع والتغيير والمستقبل. بغداد: دار الكتب والوثائق.

• السلامـات، محمود. (r • (r). فاعلية استخدام إستراتيجية (PDEODE) لطلبة المرحلة الأساسية

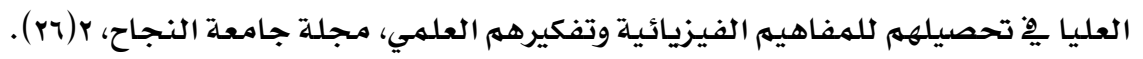

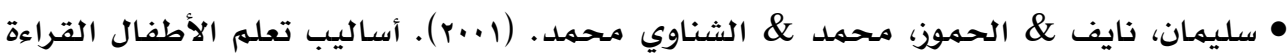

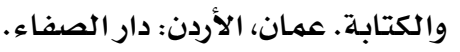

• سيد غيث الشاعر. (r.lV) ) فنيات الكتابة الأدبية. وادي النيل للنشر.

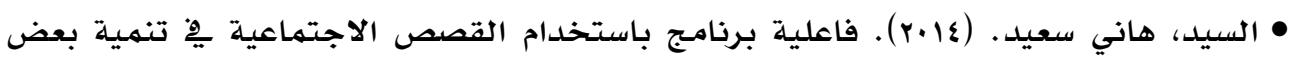

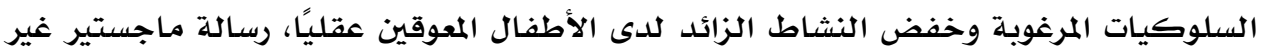
منشورة، كلية التربية، جامعة الزقازيق.

• الشاهين، بن حمد (11 +r) . معجم المصطلحات المتعلقة بالفن والتربية الفنية.

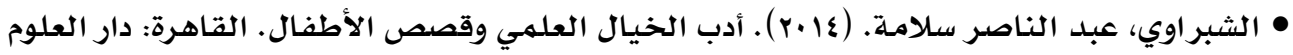
للنشروالتوزيع. • صحصاح، الأمير. (19 •r) . نشأة القصة القصيرة وتطورها ِِّ الصحافة المصرية. القاهرة: دار الادهم للنشر والتوزيـع.

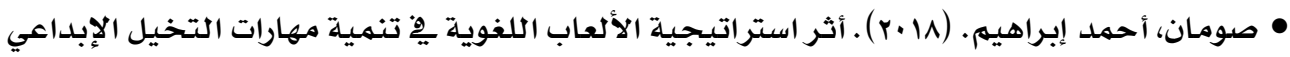

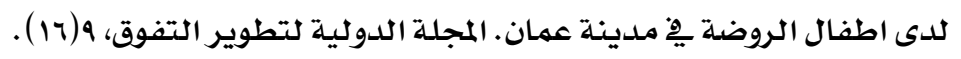

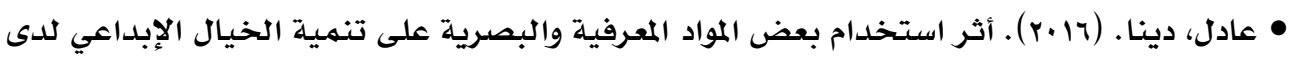

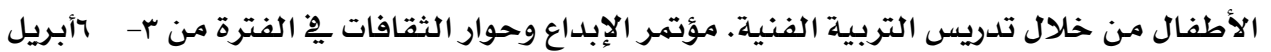
.r.17

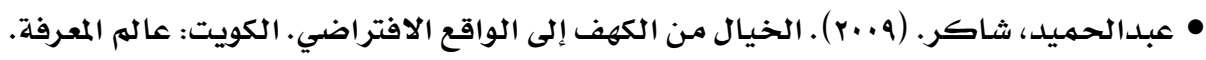

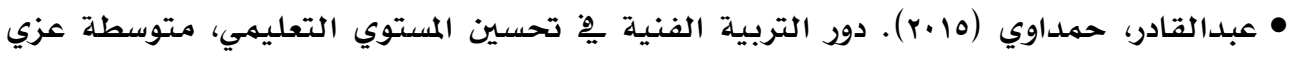

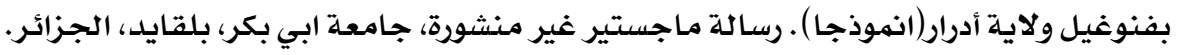

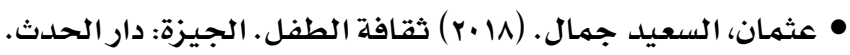

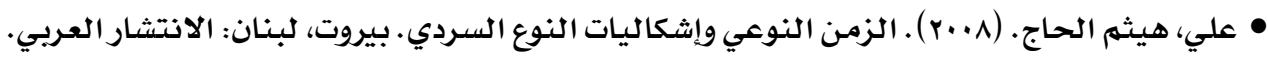

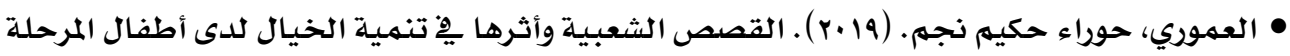

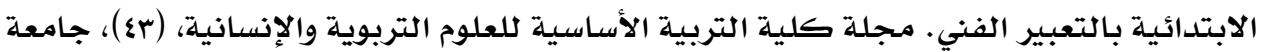
بابل. 


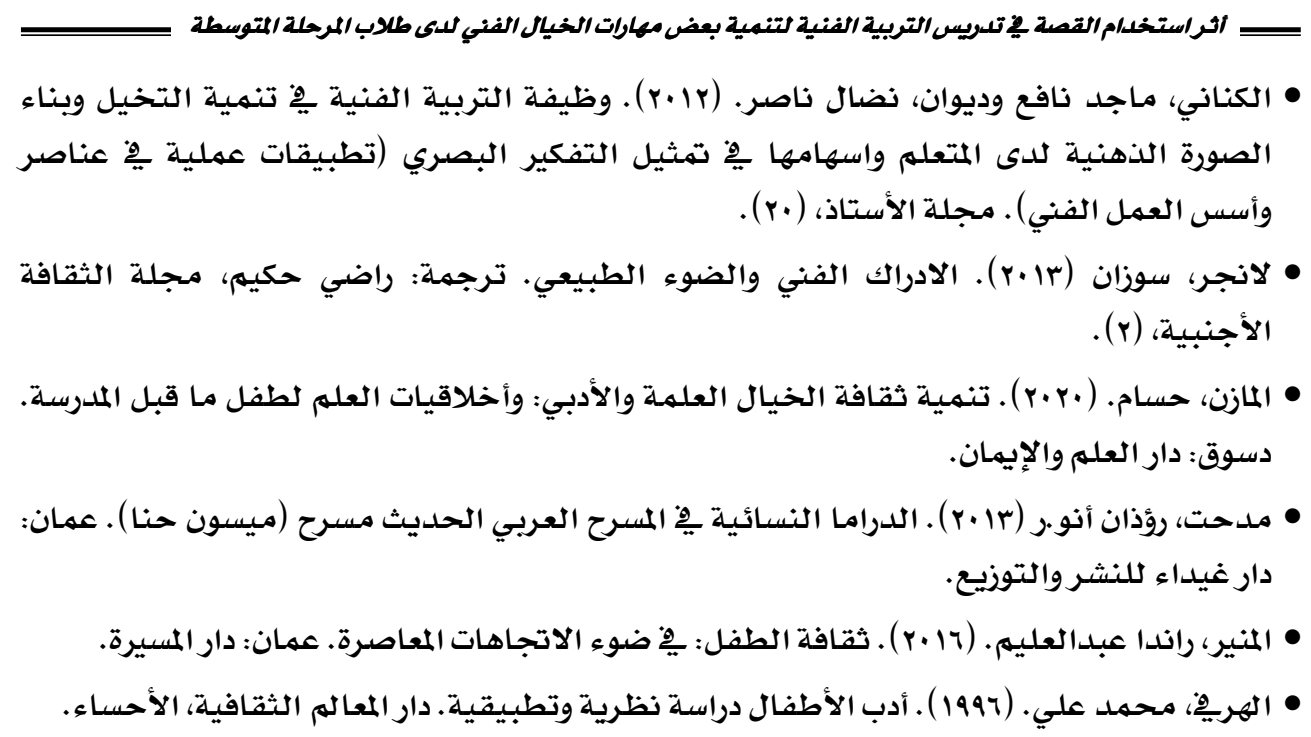

- Agar, V. (2018) Student Art Assessments, Teacher Evaluations, and Job Satisfaction among Art Teachers - Thomas University.

- Ahmad, A. (2012). Use of Short Stories as a Tool of Teaching Reading in English as Foreign Language. Journal of Educational Research (1027-9776)، 15(2).

- Al-Balushi, S.M (2003). Exploring Omani Pre-Service Science Teachers Imaginathion، at the Microscopic Level in chemistry، and their Use of the Particulate Nature of Matter in their Explanathions PhD Dissertation. Iowa City. Iowa، USA the university of Iowa.

- Al-Mansour, N. S. (2011). The effect of teacher's storytelling aloud on the reading comprehension of Saudi elementary stage students. Journal of King Saud University-Languages and Translation، 23(2)، 69-76.

- Arnheim, R (2013). A plea for visual thinking, the university of chieago press, 6(3), pp 489-497.

- Bickmore, B. Thompson،K. Grandy،D. Tomlin،T. (2009). Science As Storytelling for Teaching The Nature of Science and the ScienceReligion Interface. Journal of Geoscience Education، 57 (3)،178-190.

- Collins، R.، \& Cooper، P. J. (2005). The power of story: Teaching through storytelling. Wavelan 


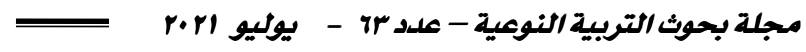

- Duh, M. , Čagran, B. and Huzjak, M. (2011) Quality and Quantity of Teaching Art Appreciation The Effect of School Systems on Students' Art Appreciation Faculty of Education, University of Maribor Faculty of Teacher Education, University of Zagreb.

- Handayani، M. P. (2013). Using children short stories to enhance studentsreading comprehension. Journal of English and Education، 1(1)، 133-141.

- Myers، W.، \& Antonelli، P. (2012). Bio Design: Nature. Science، Creativity.

- Oxford Dictionary. (2018) Online:

https://en.oxforddictionaries.com/definition/imagination.

- Upadhyayar B.R. (2005): Using students lived experiences in urban science classroom: An elementary school teacher thinking.

- Valkanova، Y.، \& Watts، M. (2007). Digital story telling in a science classroom: reflective self-learning (RSL) in action. Early Child Development and Care، 177(6-7)، 793-807.Visvanathan، G. (2016). ELearning and ICT in distance education. New Delhi: Dominant. 


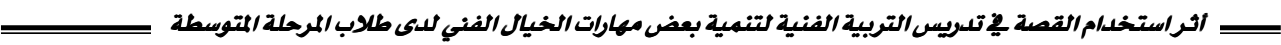

\section{The effect of using the story in teaching art education to develop some artistic imagination skills among middle school students}

\section{Abstract}

The research aimed at developing artistic imagination skills among middle school students using the teaching of art education using the story, and the research sample consisted of one experimental group of (30) male and female students. The research was based on the quasi-experimental approach, given the relevance of this design to the research variables, and the research relied on tools The following: a list of artistic imagination skills needed for second-grade intermediate students, prepared by the researcher, a scale of artistic imagination skills for intermediate second grade students, prepared by the researcher, The results of the research resulted in a statistically significant difference at a level of statistical significance (0.01) between the mean scores of the students in both the pre and post measurements on the dimensions and the total score of the technical imagination skills scale for middle school students in favor of the post measurement. Which indicates the effectiveness of the story in teaching art education in developing some artistic imagination skills among middle school students.

Keywords: story; Art education; Artistic imagination skills; Middle school student 